\title{
Distinct Self-recognition in the Prunus S-RNase-based Gametophytic Self-incompatibility System
}

\author{
Daiki Matsumoto ${ }^{1}$ and Ryutaro Tao ${ }^{2 *}$ \\ ${ }^{1}$ Faculty of Agriculture, Yamagata University, Tsuruoka 997-8555, Japan \\ ${ }^{2}$ Graduate School of Agriculture, Kyoto University, Kyoto 606-8502, Japan
}

\begin{abstract}
Prunus fruit tree species exhibit S-ribonuclease (S-RNase)-based gametophytic self-incompatibility (GSI). This system is also present in the families Plantaginaceae and Solanaceae and the tribe Maleae of the family Rosaceae. In S-RNase-based GSI, self/nonself-recognition between the pistil and pollen is controlled by the pistil $S$ determinant S-ribonuclease gene ( $S$-RNase) and the pollen $S$ determinant F-box gene(s). Accumulated evidence indicates the Prunus pollen $S$ locus contains a single F-box gene, while that of other plants consists of multiple F-box genes. The pollen $S$ F-box genes are called $S$ haplotype-specific F-box (SFB), $S$-locus F-box brothers (SFBB), and S-locus F-box (SLF) in Prunus, Maleae, and Solanaceae species, respectively. The consequences of pollen $S$ gene mutations and heterodiallelic pollen production differ between Prunus species and other plants, suggesting there are different pollen $S$ functions during self/nonself-recognition. The GSI systems of Prunus and other plants are believed to include the ubiquitin proteasome system for protein degradation. However, Prunus SFB is assumed to facilitate the S-RNase cytotoxic effects during selfrecognition, while SLFs and SFBBs are thought to function collaboratively during nonself-recognition to avoid S-RNase cytotoxicity. This review summarizes the distinct features of the S-RNase-based GSI mechanism in Prunus species, with special references to the recent advances in our understanding of S-RNase-based GSI.
\end{abstract}

Key Words: general inhibitor, pollen $S$ determinant, SCF complex, self/nonself-recognition.

\section{Introduction}

The genus Prunus L. is classified in the tribe Amygdalae within the subfamily Amygdaloideae in the family Rosaceae. It consists of over 200 species distributed across the northern hemisphere, including several economically important cultivated species, which are horticulturally often referred to as stone fruits (McNeill et al., 2012; Potter et al., 2007). Successful pollination, fertilization, and seed formation are indispensable to Prunus species fruit production because they do not bear fruit parthenocarpically. In addition to the absence of parthenocarpic ability, fruit set in Prunus species is hindered by a prezygotic reproductive barrier called the self-incompatibility (SI) system, which allows pistils to reject pollen from self and genetically related individu-

Received; February 11, 2016. Accepted; February 28, 2016.

First Published Online in J-STAGE on April 27, 2016.

This work was supported by Grant-in-Aid (nos. 20248004, 24248007 and $15 \mathrm{H} 02431$ ) for Scientific Research (A) from Japan Society for the Promotion of Science (JSPS) to R.T.

* Corresponding author (E-mail: rtao@kais.kyoto-u.ac.jp). als (de Nettancourt, 2001; Tao and Iezzoni, 2010). The mode of Prunus SI is classified as gametophytic SI (GSI), where pollen specificity is determined based on its own haploid genome (Fig. 1). Prunus SI specificity is controlled by a single polymorphic $S$ locus harboring pistil $S$ and pollen $S$ determinant genes, and variants of the $S$ locus are referred to as $S$ haplotypes. When the $S$ haplotype of the pollen matches either of the two $S$ haplotypes of the pistils, the pollen is recognized as selfpollen and the pollen tube stops growing in the style (de Nettancourt, 2001). In commercial orchards, simultaneously flowering cross-compatible cultivars belonging to different incompatibility groups are required to ensure sufficient fruit set.

During the late 1990s to early 2000s, S-ribonuclease (S-RNase) and F-box genes were identified as the pistil $S$ and pollen $S$ genes in Prunus species, respectively (Entani et al., 2003; Sonneveld et al., 2005; Tao et al., 1997, 1999; Ushijima et al., 1998, 2003, 2004; Yamane et al., 2003b). These findings led to the development of polymerase chain reaction-based $S$ haplotyping, which is a fast, accurate, and stable method to determine the $S$ haplotype. This procedure has been widely and success- 
fully used to re-evaluate $S$ haplotypes of cultivars, and has recently been used in Prunus fruit tree breeding programs (Beppu et al., 2003; Habu et al., 2008; Ikeda et al., 2004b; Sonneveld et al., 2001, 2003; Sutherland et al., 2004; Tao et al., 1999; Yamane and Tao, 2009; Yamane et al., 2003c, 2009). Although these advances make it possible to circumvent some of the problems related to SI, further characterizing the underlying molecular mechanism is necessary to artificially control GSI in Prunus species.

(A) Self-pollination

Cross-pollination
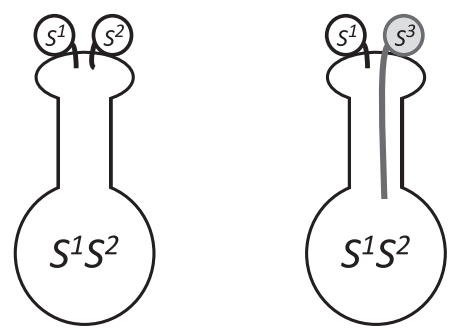

(B)

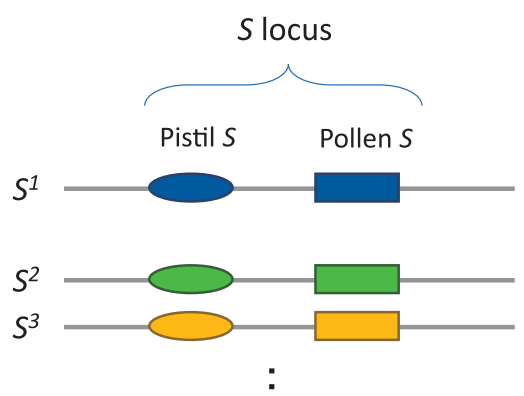

Fig. 1. Genetic control of gametophytic self-incompatibility (GSI). (A) In GSI, the pollen is rejected when its $S$ haplotype matches either of the pistil $S$ haplotypes. The cross is incompatible when the $S$ haplotypes of the male and female parents match completely $\left(S^{l} S^{2} \times S^{l} S^{2}\right)$, while the cross is compatible when a portion of the $S$ haplotypes is shared by the male and female parents $\left(S^{l} S^{2} \times S^{l} S^{3}\right)$. (B) The GSI is generally controlled by a single $S$ locus, which contains at least two genes, one for pollen specificity and another for pistil specificity.
The GSI system involving S-RNase as its pistil $S$ determinant has been detected in the tribe Maleae of the family Rosaceae, as well as in the families Solanaceae, Plantaginaceae, and Rubiaceae (Anderson et al., 1986; Asquini et al., 2011; McClure et al., 1989; Nowak et al., 2011; Sassa et al., 1992, 1993, 1996; Xue et al., 1996). Phylogenetic analyses of S-RNase and its related sequences have revealed that the S-RNase-based GSI system has a single evolutionary origin, dating back about 120 million years (Igic and Kohn, 2001; Steinbachs and Holsinger, 2002; Vieira et al., 2008a). The F-box genes have been commonly identified as the pollen $S$ determinants, except in the family Rubiaceae, which was recently observed to exhibit the S-RNase-based GSI with no identified pollen $S$ determinant. Based on the similarities of the $S$ determinant molecules, the molecular mechanism regulating Prunus GSI was assumed to be similar to that of the S-RNase-based GSI in plants from the family Solanaceae, as well as other plants. The features of the Prunus GSI molecular mechanism that distinguish it even from the corresponding systems in plants from the sister tribe Maleae have been identified, as the functional aspects of pollen $S$ F-box proteins in different plant families have become characterized (Table 1, discussed below in detail; de Franceschi et al., 2012; McClure et al., 2011; Meng et al., 2010; Tao and Iezzoni, 2010). Currently, the Prunus pollen $S$ F-box protein is assumed to function in self-recognition, while those in other plant families appear to function in nonself-recognition. Interestingly, recent genome-wide studies have suggested duplication events involving the $S$ locus occurred in ancestral rosaceous species, and plants from the genus Prunus and tribe Maleae adopted different paralogs as specificity determinants (Aguiar et al., 2015; Morimoto et al., 2015). Although the Prunus-specific mechanism is still largely uncharacterized, an increasing number of studies have been conducted to clarify the molecular basis of Prunus GSI recognition.

This review summarizes the current information regarding the distinct molecular recognition mechanism

Table 1. Summary of the pollen $S$ gene characteristics in different plant taxa exhibiting S-RNase based gametophytic self-incompatibility.

\begin{tabular}{|c|c|c|c|c|c|}
\hline \multirow{2}{*}{$\begin{array}{l}\text { Plant family } \\
\text { (subfamily) }\end{array}$} & \multirow{2}{*}{ Tribe } & \multirow{2}{*}{ Representative SI genera } & \multicolumn{3}{|c|}{ Pollen $S$} \\
\hline & & & entity & gene name & proposed function \\
\hline \multirow[t]{2}{*}{$\begin{array}{l}\text { Rosaceae } \\
\text { (Amygdaloideae) }\end{array}$} & Amygdalae & Prunus & Single gene & $S F B$ & $\begin{array}{l}\text { Self-recognition to trigger S-RNase } \\
\text { cytotoxicity }\end{array}$ \\
\hline & Maleae & Malus, Pyrus & Multiple paralogs & $S F B B x^{2}$ & $\begin{array}{l}\text { Nonself-recognition to inhibit } \\
\text { S-RNase cytotoxicity }\end{array}$ \\
\hline Solanaceae & & Petunia, Nicotiana, Solanum & Multiple paralogs & $S L F x^{z}$ & $\begin{array}{l}\text { Nonself-recognition to inhibit } \\
\text { S-RNase cytotoxicity }\end{array}$ \\
\hline Plantaginaceae & & Antirrhinum & $\begin{array}{l}\text { Multiple paralogs } \\
\text { (putative) }\end{array}$ & $\operatorname{SLF}(x)^{\mathrm{z}}$ & $\begin{array}{l}\text { Nonself-recognition to inhibit } \\
\text { S-RNase cytotoxicity }\end{array}$ \\
\hline Rubiaceae & & Coffea & unknown & unidentified & - \\
\hline
\end{tabular}

${ }^{\mathrm{z}} \mathrm{x}$ corresponds to a specific number that distinguishes paralogs 
of the Prunus S-RNase-based GSI. We first describe the characteristics of the $S$ determinants and the common SRNase-based GSI molecular mechanism detected in non-Prunus taxa. We then introduce the Prunus-specific consequences of mutations in the pollen $S$ locus and heteroallelic pollen (HAP) production. Based on these outcomes, we discuss the distinct molecular mechanism of Prunus S-RNase-based GSI, with special reference to the recent advances in our understanding of SRNase-based GSI.

\section{Identification and Characterization of S-RNase}

S-RNase was first identified in Nicotiana alata as a stylar basic glycoprotein (approximately $30 \mathrm{kDa}$ ) for which the gene co-segregated with its pistil $S$ allele (Anderson et al., 1986). Later, it was revealed that the stylar glycoprotein exhibited RNase activity, and its sequence was homologous to that of Aspergillus RNaseT2 (McClure et al., 1989). Transformation experiments in Nicotiana and Petunia species confirmed that SRNase loss-of-function leads to self-compatibility (SC) because of an inability to reject self-pollen. In contrast, S-RNase gain-of-function confers the ability to reject pollen with the newly introduced $S$ haplotype. This indicates $S$-RNase is the sole pistil $S$ gene of GSI in the family Solanaceae, and the encoded enzyme likely has cytotoxic effects against self-pollen (Lee et al., 1994; Murfett et al., 1994).

In the 1990s, following the identification of the pistil $S$ locus in the family Solanaceae, S-RNase genes were cloned as the pistil $S$ gene candidates in Antirrhinum species from the family Plantaginaceae, Pyrus and Malus species from the tribe Maleae of the family Rosaceae, and Prunus species from the family Rosaceae (Brootharerts et al., 1995; Sassa et al., 1992, 1993, 1996; Tao et al., 1997, 1999; Ushijima et al., 1998; Xue et al., 1996). The S-RNases of other genera in the tribe Maleae, including Crataegus, Eriobotrya, and Sorbus, and those of the family Rubiaceae were also isolated (Asquini et al., 2011; Carrera et al., 2009; Nowak et al., 2011; Raspé and Kohn, 2002). Transformation experiments in Malus species and analyses of the loss-of-function mutants in Pyrus and Prunus species indicated that Rosaceae S-RNase genes were the sole pistil $S$ genes, and encoded enzymes that were assumed to be cytotoxic to self-pollen (Brootharerts et al., 2004; Hanada et al., 2009; Sanzol, 2009; Sassa et al., 1997; Watari et al., 2007; Yamane et al., 2003a).

The S-RNases from these families share many common features, although there is insufficient information regarding Rubiaceae S-RNases. All reported S-RNases are specifically expressed in the pistil, with high expression levels in the style (Anderson et al., 1986; Asquini et al., 2011; Nowak et al., 2011; Tao et al., 1999; Xue et al., 1996). In situ hybridization results indicated S-RNases are preferentially expressed in transmitting tissue tract cells of the style in the families
Solanaceae and Plantaginaceae (Anderson et al., 1989; Xue et al., 1996). An N-terminal secretion signal (i.e., signal peptide) is common in S-RNases, indicating they localize in the extracellular matrix of transmitting tissues, through which pollen tubes elongate, as observed in the family Solanaceae and tribe Maleae (Anderson et al., 1989; Certal et al., 1999). These features reflect the nature of the interaction between S-RNase and pollen.

S-RNase is a glycoprotein exhibiting RNase activity, which requires the presence of a well-conserved catalytic core motif consisting of two His residues. Transgenic experiments and mutant analyses in the family Solanaceae demonstrated that replacing the conserved His residues in S-RNase resulted in SC, indicating RNase activity is essential for S-RNase cytotoxicity during the SI reaction (Huang et al., 1994; Kowyama et al., 1994). RNase activity in a Maleae SC haplotype is absent, possibly because of an amino acid insertion in the region facing the active site (Nyska et al., 2013). Although S-RNases exhibit diversity in the number and position of N-glycosylation sites depending on the alleles, the functions of N-linked glycans in self/nonselfrecognition is still unclear. Analyses of Petunia and Solanum species using a recombinant non-glycosylated S-RNase indicated that carbohydrate moieties are not required to determine specificity or the SI reaction (Karunanandaa et al., 1994; Soulard et al., 2013). Soulard et al. (2013) also reported that recombinant SRNase lacking its innate N-glycosylated sites, but with an artificially inserted N-glycosylation site in its hypervariable region, exhibited dual specificity. This enabled the recognition of an additional nonself $S$ haplotype in addition to the original self $S$ haplotype. It was suggested that a decrease in the number of S-RNase glycosylation sites may be related to a lower threshold for self-pollen rejection (Liu et al., 2008).

Analyses of the primary structure of solanaceous SRNases identified five conserved domains (C1-C5) and two hypervariable (HV) regions ( $\mathrm{HVa}$ and $\mathrm{HVb}$ ), both of which are located between $\mathrm{C} 2$ and $\mathrm{C} 3$ (Fig. 2; Ioerger et al., 1991). The conserved domains are assumed to be important for maintaining the basic three dimensional structure of a functioning S-RNase. In fact, domains $\mathrm{C} 2$ and $\mathrm{C} 3$ each contain one of the two His residues required for enzymatic activity. An investigation of the enzyme crystal structure revealed $\mathrm{C} 1, \mathrm{C} 2$, and $\mathrm{C} 5$ comprised the RNase active site (Ida et al., 2001). Additionally, the conserved N-glycosylation site is located in the $\mathrm{C} 2$ domain. Although the role of the $\mathrm{C} 4$ region remains unknown, transgenic experiments involving amino acid substitutions indicated that none of the $\mathrm{C} 4$ amino acid residues are important for the SI reaction (Qin et al., 2005). The HVa and HVb regions exhibit high sequence variability and are located on the surface of the crystal structure, which make them prime candidates for the $S$ specificity-determining regions (Ida 


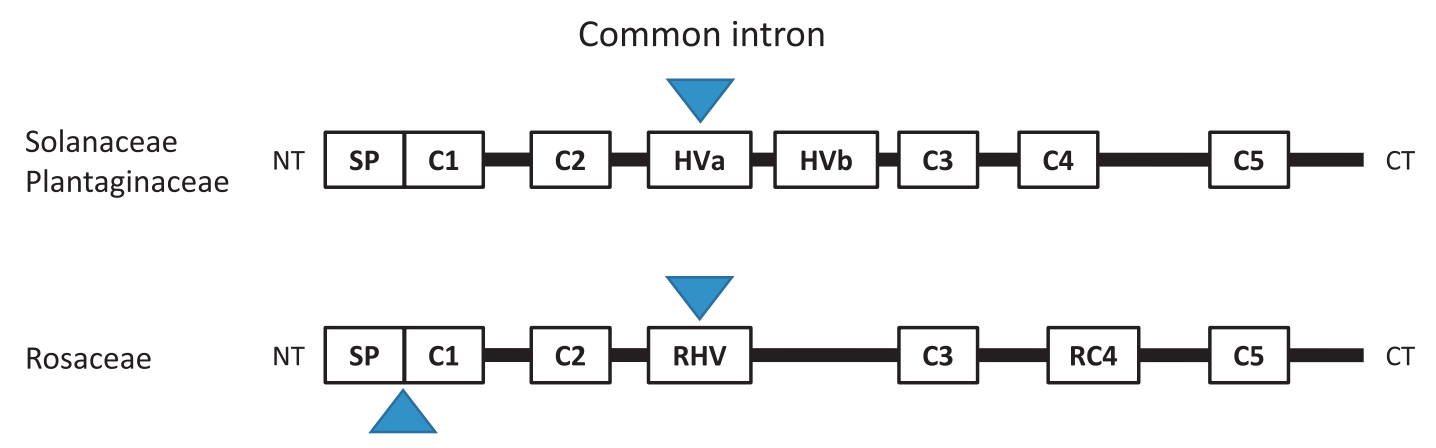

\section{Prunus-specific intron}

Fig. 2. S-RNase protein structures. Triangles indicate intron locations. S-RNase genes of all plant families that exhibit S-RNase-based gametophytic self-incompatibility have an intron located in hypervariable region a (HVa) or the rosaceous hypervariable region (RHV). The intron located between the signal peptide and the C1 region is present only in Prunus S-RNase genes. SP: signal peptide; C1-C5: conserved regions; HVb: hypervariable region b; RC4: rosaceous conserved region; NT: amino-terminus; CT: carboxyl-terminus.

et al., 2001; Ioerger et al., 1991). However, a series of experiments in which chimeric S-RNases were expressed in transgenic plants led to inconsistent conclusions about the roles of HV regions, suggesting they had necessary, but insufficient, roles in determining specificity (Kao and McCubbin, 1996; Matton et al., 1997; Zurek et al., 1997).

The S-RNases of species from families other than Solanaceae contain structural features similar to those of solanaceous S-RNases. For example, plantaginaceous S-RNases have five conserved regions and two hypervariable regions. However, there is little sequence homology between the $\mathrm{C} 4$ regions of Plantaginaceae and Solanaceae S-RNases (Xue et al., 1996). Rosaceous S-RNases differ from solanaceous S-RNases more than plantaginaceous S-RNases (Fig. 2). Although rosaceous S-RNases have structural characteristics similar to those of S-RNases from other plants, their $\mathrm{C} 4$ and $\mathrm{HV}$ regions are distinct (Ushijima et al., 1998). Rosaceous SRNases possess a fourth conserved domain, called RC4, which differs from the $\mathrm{C} 4$ region of solanaceous and plantaginaceous S-RNases regarding position and amino acid sequence. Furthermore, only a single rosaceous HV (RHV) region has been detected in the position corresponding to that of HVa (Ishimizu et al., 1998; Ushijima et al., 1998). Interestingly, the amino acid sites under positive selection in solanaceous S-RNases, where non-synonymous substitutions are preferred to synonymous substitutions, are located mainly in the $\mathrm{HVa}$ and $\mathrm{HVb}$ regions. In contrast, sites under positive selection in rosaceous S-RNases are distributed over their entire sequence, except for the region encoding the $\mathrm{N}$-terminal secretion signal (Ishimizu et al., 1998; Ortega et al., 2006; Vieira et al., 2007, 2010). These results suggest that the RHV region may not be the only one with a significant role in determining specificity in rosaceous S-RNases. This possibility is supported by the fact that the same RHV sequence is present in different $S$-RNase alleles that exhibit diverse specificities (Matsumoto et al., 2010; Ortega et al., 2006; Zisovich et al., 2004). Furthermore, the conserved Nglycosylation site of rosaceous S-RNases is located in $\mathrm{RC} 4$, whereas it is located in $\mathrm{C} 2$ in the S-RNases of all other plants.

Phylogenetic analyses of S-RNases from different families have revealed their shared origin, as well as lineage-specific clustering (Igic and Kohn, 2001; Nowak et al., 2011; Steinbachs and Holsinger, 2002; Vieira et al., 2008a). Their intron structures also reflected lineage specificity. A single intron is present in the coding sequences of Solanaceae, Plantaginaceae, and Maleae $S$-RNase genes. There is an additional intron in the coding sequence located downstream of the secretion signal in Prunus S-RNase genes (Fig. 2; Tao et al., 1999). S-RNases acquired different features as they evolved, even if they retained their cytotoxicity to self-pollen.

\section{Identification of F-Box Genes as the Pollen $S$ Gene Candidate}

The pollen $S$ locus involved in S-RNase-based GSI has been extensively studied in terms of its expected characteristics, such as its complete linkage to $S$-RNase, allele-specific sequence polymorphisms, and pollenspecific expression. Map-based cloning and chromosome walking approaches to study the Solanaceae, Plantaginaceae, and Rosaceae $S$ loci have commonly identified multiple pollen-expressed F-box genes flanking the S-RNase gene (Fig. 3; de Franceschi et al., 2011; Entani et al., 2003; Lai et al., 2002; Minamikawa et al., 2010; Okada et al., 2008, 2010, 2013; Sassa et al., 2007; Ushijima et al., 2001, 2004; Wang et al., 2003, 2004; Wheeler and Newbigin, 2007; Zhou et al., 2003). Compared with that of the genus Prunus, the recombination-suppressed region around the $S$ locus is much larger and more highly heterochromatic in the tribe Maleae and the families Solanaceae and Plantaginaceae, making it difficult to isolate the true pollen $S$ gene in these three plant taxa (Entani et al., 1999a; Wang et al., 2012; Yang et al., 2007). This 


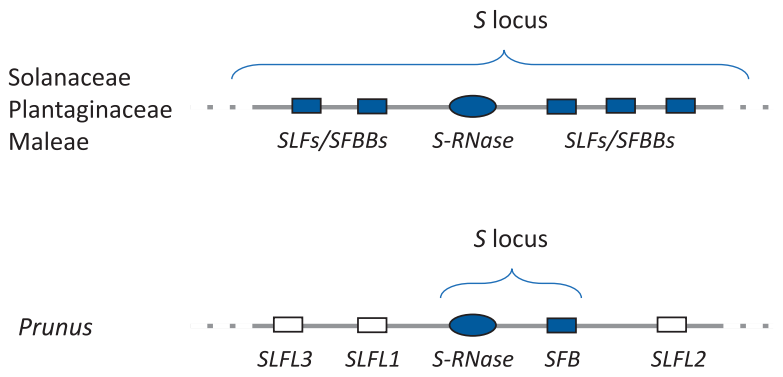

Fig. 3. Schematic diagram of the $S$ locus controlling S-RNasebased gametophytic self-incompatibility. Multiple F-box genes expressed in pollen are located around the $S$-RNase gene in all plant families. In the tribe Maleae and the families Solanaceae and Plantaginaceae, the $S$ loci can be more than several $\mathrm{Mb}$ and contain multiple F-box genes, each of which acts as a pollen $S$ gene. In contrast, the Prunus $S$ locus is as small as approximately $70 \mathrm{~kb}$, and contains a single pollen $S$ F-box gene, $S F B$. Other pollen-expressed F-box genes (e.g., SLFL1-3) flank the $S$ locus. The Prunus SLFL1-3 genes are not involved in determining pollen specificity.

region was estimated to be $4.4 \mathrm{Mb}$ in Petunia species, at least $1 \mathrm{Mb}$ in Malus species, and could be as small as about $70 \mathrm{~kb}$ in Prunus species (Entani et al., 2003; Ushijima et al., 2001, 2003; Wang et al., 2003, 2012).

The pollen $S$ candidate F-box genes (except for those in Prunus species) exhibit a lower level of allelic sequence polymorphism than expected based on the allelic sequence diversity of $S$-RNases. The Solanaceae and Plantaginaceae F-box genes are referred to as $S$-locus F-box $(S L F)$ or SLF-like $(S L F L)$ genes. In the tribe Maleae, the pollen $S$ candidate F-box genes are named $S$-locus F-box brothers ( $S F B B S$ ). The pollen $S$ candidate F-box genes of the families Solanaceae and Plantaginaceae and the tribe Maleae exhibit high allelic amino acid sequence identities of $86.4 \%-100 \%, 90 \%$ $98.6 \%$, and $83.2 \%-99 \%$, respectively, which are much higher than the sequence identities of their corresponding S-RNases (i.e., 40.1\%-79.4\%, 40\%-55\%, and $58.0 \%-92.5 \%$, respectively) (Kakui et al., 2011; Kubo et al., 2010; Xue et al., 1996; Zhou et al., 2003). In contrast, a single Prunus F-box gene located in the $S$ locus had high allelic sequence polymorphisms $(66 \%-82.5 \%$ amino acid identities), which were equivalent to the allelic sequence polymorphisms in S-RNase $(54.6 \%$ $82.5 \%$ ). The Prunus F-box gene was identified as a pollen $S$ gene candidate, and two research groups gave it different names, SLF and $S$ haplotype-specific F-box (SFB) (Entani et al., 2003; Ikeda et al., 2004a; Ushijima et al., 2003, 2004; Yamane et al., 2003b). In this review, the term $S F B$ is used to reflect its features that differ from the pollen $S$ gene of other plants with S-RNasebased GSI.

\section{Collaboration of Multiple F-Box Genes to Determine Specificity in Taxa Other than Prunus}

After pollen $S$ gene candidates were identified, transgenic and mutant analyses were used to identify the true
(A)

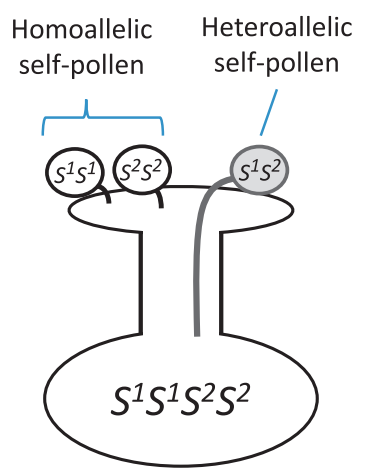

(B)
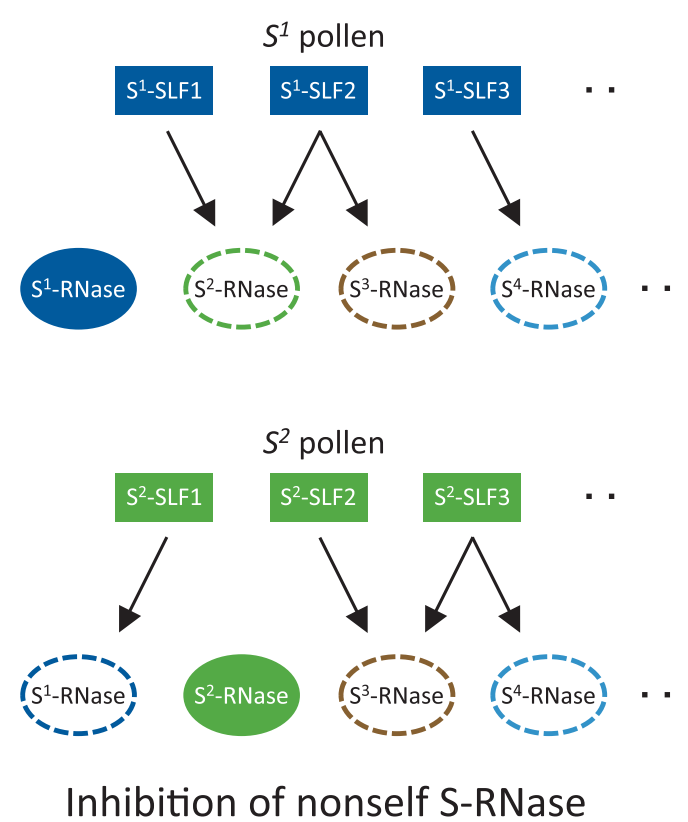

Fig. 4. Function of the pollen $S$ locus during the inhibition of nonself S-RNases in the tribe Maleae and families Solanaceae and Plantaginaceae. (A) Tetraploid plants exhibit self-compatibility, which is conferred by heteroallelic pollen. This selfcompatibility results from the inhibition of all S-RNases through the complementary effects of two pollen $S$ genes. (B) Nonself recognition by multiple pollen $S$ F-box proteins, each of which recognizes and inhibits a subset of nonself S-RNases. Additionally, a complete set of pollen $S$ F-box proteins function against everything but self S-RNases.

pollen $S$ gene. Early mutagenesis studies in the family Solanaceae revealed that a single pollen grain containing two different pollen $S$ alleles (i.e., HAP) became self- and cross-compatible, indicating that the pollen $S$ gene functions as an inhibitor of nonself S-RNase (Fig. 4A; Entani et al., 1999b; Golz et al., 1999, 2001). This phenomenon, called competitive interaction, can be explained by assuming the pollen $S$ gene product inhibits everything but self S-RNase. Competitive interactions have also been observed in the family Plantaginaceae and the tribe Maleae (Adachi et al., 2009; Lewis and Modilbowska, 1942; Mase et al., 2014; Qi et al., 2011; Sassa et al., 2009; Xue et al., 2009). Transgenic studies determined that the integra- 
tion of an additional F-box allele from a different $S$ haplotype resulted in SC by inducing the competitive interaction (Qiao et al., 2004b; Sijacic et al., 2004). Based on these studies, it was suggested that a single F-box gene corresponded to the pollen $S$ gene in these plant families, and the single F-box gene was named $S L F$ to indicate it is a true pollen $S$ gene, while the other F-box genes in the $S$ locus were referred to as $S L F L$.

However, recent studies revealed there are elements in addition to the pollen $S$ gene in the family Solanaceae. Kubo et al. (2010) reported that two SLFL genes (renamed as $S L F 2$ and $S L F 3$; see below) could also induce competitive interactions in pollen grains of certain $S$ haplotypes. This indicated $S L F$ and $S L F L$ genes function together as the pollen $S$ gene. The $S L F$ and $S L F L$ genes cloned from pollen were classified into six subgroups, with the $S L F$ gene renamed as type-1 $S L F(S L F 1)$ and the SLFL genes renamed as type-2-6 SLF (SLF2-6). To date, 16-20 SLF genes have been identified in each $S$ haplotype, and are classified into 18 types in Petunia species (Kubo et al., 2015; Williams et al., 2014a, b). Of these, SLF1-6, -8, and -9 were confirmed to cause competitive interactions in certain $S$ haplotypes. Each SLF can inhibit a subset of S-RNases, and a set of all SLFs in a given $S$ haplotype is assumed to inhibit all nonself S-RNases. Several SLFs appear to target the same S-RNase, as indicated by the fact silencing of one $S L F$ does not necessarily result in crossincompatibility (Sun and Kao, 2013).

The presence of multiple pollen $S$ factors is also consistent with observations in the tribe Maleae. Mutant analyses indicated SFBB1 of the Pyrus pyrifolia $S^{4}$ haplotype is required for pollen tube growth in a pistil producing $\mathrm{S}^{1}$-RNase, indicating multiple $S F B B$ genes, including $S F B B 1$, confer cross-compatibility (Kakui et al., 2011; Okada et al., 2008; Saito et al., 2012). Although only two or three types of SFBB were reported when they were initially discovered, at least 8,11 , and 16 types have subsequently been identified in the genera Pyrus, Malus, and Sorbus, respectively (Aguiar et al., 2013; Kakui et al., 2011; Okada et al., 2013; Sassa et al., 2007). Furthermore, in contrast to the low sequence polymorphism observed among alleles of the same type of $S F B B$, synonymous and non-synonymous substitution rates among different types of $S F B B$ were comparable to those among different $S$-RNase alleles (Kakui et al., 2011). This suggests the diversification of SI specificity was due to the duplication and differentiation of the $S F B B$ loci as well as the diversification of $S$ RNase alleles. Aguiar et al. (2013) reported that the most closely related Sorbus SFBB genes diverged 8.27 million years ago (MYA). The most distantly related $S F B B$ genes diverged 23.96 MYA, which is similar to the age of the oldest Maleae S-RNase specificity lineage (approximately 23 million years old; Vieira et al., 2010).

Considered together, several lines of recent evidence indicate the Solanaceae and Maleae pollen $S$ locus consists of multiple $S L F$ and $S F B B$ F-box genes, respectively, and each F-box protein inhibits a subset of nonself S-RNases (Fig. 4B). Although there has been no report describing the multiplicity of the plantaginaceous pollen $S$, a very low level of $S L F$ allelic sequence polymorphism (i.e., 97\%-99\% amino acid identities) may indicate the existence of multiple F-box genes at the pollen $S$ locus.

\section{Molecular Mechanism of Self/Nonself Discrimination by Multiple F-Box Genes}

A protein degradation model for the self/nonself discrimination mechanism was developed based on the expected biochemical functions of an F-box protein (Meng et al., 2010; Ushijima et al., 2004). An F-box protein forms part of the SCF complex, which consists of Skp1, Cul1, and Rbx1 (Deshaies and Joazeiro, 2009). The SCF complex is one of the RING-type E3 ubiquitin ligases, which polyubiquitinates substrate proteins to be degraded by the ubiquitin proteasome system (UPS). In the SCF complex, the F-box protein determines substrate specificity, Skp1 serves as an adaptor to connect variable F-box proteins to Cul1, and Cull forms a core catalytic scaffold with Rbx1 (Zheng et al., 2002). The $\mathrm{Rbx} 1$ component recruits the ubiquitin-charged E2 enzyme with its zinc finger domain, and the ubiquitin moiety is transferred from E2 to the substrate. The protein degradation model proposed that the SCF complex with the pollen $S$ gene product, which was once assumed to be a single element, recognize and polyubiquitinate all nonself S-RNases (but not self S-RNases) for degradation (Fig. 5). This nonself-recognition is considered to be completed through the collaborative activities of multiple pollen $S$ F-box proteins (Iwano and Takayama, 2012; Kubo et al., 2010; Wang and Kao, 2012). A series of biochemical experiments have provided data supporting this nonself S-RNase degradation model.

Pollen $S$ F-box proteins from the families Solanaceae and Plantaginaceae and the tribe Maleae, were confirmed to form SCF complexes with the Skp1-like protein SSK1 (Huang et al., 2006; Li et al., 2014; Minamikawa et al., 2014; Xu et al., 2013; Yuan et al., 2014; Zhao et al., 2010). In Solanaceae species, downregulation of either SSK1 or Cull results in a loss of cross-compatibility, indicating the indispensable role of the $\mathrm{SCF}^{\mathrm{SLF}}$ complex in compatible reactions, and the involvement of the UPS in S-RNase detoxification ( $\mathrm{Li}$ and Chetlat, 2014; Zhao et al., 2010). S-RNase binding protein 1 (SBP1) was also identified as a component of an alternative E3 ligase complexed with the pollen $S$ Fbox protein (Hua and Kao, 2006). In vitro experiments revealed that the solanaceous SBP1 interacts with SLF, Cul1, and the E2 ubiquitin-conjugating enzyme. On the contrary, recombinant solanaceous SLF expressed in pollen grains did not appear to interact with SBP1, but 
(A)

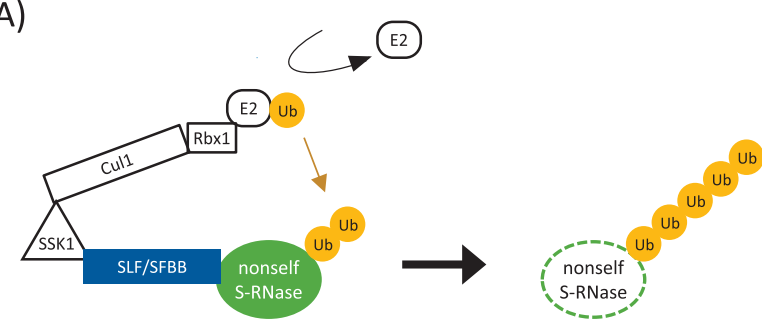

(B)

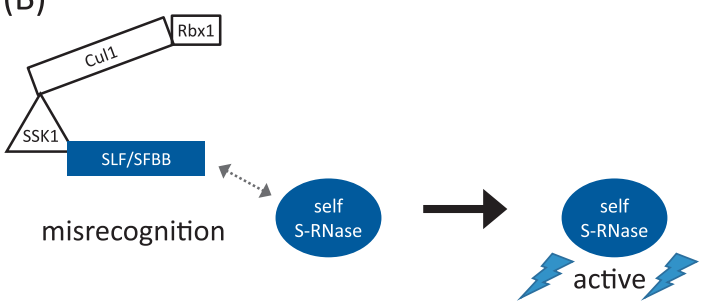

Fig. 5. The molecular basis of self/nonself discrimination in the tribe Maleae and families Solanaceae and Plantaginaceae involves a degradation model for the biochemical function of the pollen $S$ gene. (A) Inhibition of nonself S-RNases with the ubiquitin proteasome system. The SLF/SFBBs form the SCF complex with the SLF/SFBB-interacting Skp1-like protein (SSK1), Cul1, and Rbx1. The SLF/SFBB in the complex recognizes nonself S-RNases as the substrate, and $\mathrm{SCF}^{\mathrm{SLF} / \mathrm{SFBB}}$ attaches ubiquitin molecules by recruiting the E2 enzyme carrying ubiquitin. The polyubiquitinated nonself S-RNases are degraded by the $26 \mathrm{~S}$ proteasome. (B) Inability to inhibit self SRNases. The SLF/SFBBs in the complex are unable to recognize self S-RNases as the substrate because of low affinity or a self-specific interaction. Therefore, self S-RNases remain intact and their cytotoxicity induces the self-incompatibility reaction.

mainly formed a canonical SCF complex with SSK1 (Entani et al., 2014; Hua and Kao, 2006; Li et al., 2014). Although SBP1 was also identified in the tribe Maleae, inconsistent results were obtained regarding the interaction between SBP1 and SFBB. Minamikawa et al. (2014) observed that SBP1 interacted with SFBB and Cul1, which contradicted the findings of Yuan et al. (2014). Nevertheless, the possible involvement of SBP1 in SI is still unclear because SBP1 by itself was reported to interact with S-RNase in the family Solanaceae and the tribe Maleae (Hua and Kao, 2006, 2008; Minamikawa et al., 2013; Sims and Ordanic, 2001). Furthermore, polyubiquitination of S-RNase by SBP1 was observed in vitro in Solanaceae species, while no such polyubiquitination was detected in Maleae species (Hua and Kao, 2006, 2008; Yuan et al., 2014).

Selective polyubiquitination of nonself S-RNases by pollen or recombinant SLF was observed in vitro in Solanaceae and Plantaginaceae species (Chen et al., 2012; Entani et al., 2014; Hua and Kao, 2006; Qiao et al., 2004a). Additionally, a recent in vivo study in a Petunia species confirmed that S-RNase is polyubiquitinated and degraded in compatible pollen tubes, but not in incompatible ones (Liu et al., 2014). Entani et al.
(2014) reported that Petunia $S^{7}$-SLF2, which induces competitive interactions in $S^{9}$ and $S^{l l}$ pollen, but not in $S^{5}$ or $S^{7}$ pollen, polyubiquitinated S-RNases from $S^{9}$ and $S^{I l}$ haplotypes, but not from $S^{5}$ and $S^{7}$ haplotypes. These results suggest the polyubiquitination of S-RNases by the pollen $S$ F-box protein is likely involved in regulating compatibility, and that all nonself S-RNases may be degraded by multiple pollen $S$ F-box proteins in pollen tubes.

Specific self/nonself interactions between pollen $S$ F-box proteins and S-RNases are considered the basis of selective polyubiquitination. However, it is unclear how self S-RNases evade polyubiquitination by pollen $S$ F-box proteins. Several SLFs from the family Solanaceae and SFBBs from the tribe Maleae are known to interact with a subset of nonself S-RNases. Additionally, some SLFs from Solanaceae and Plantaginaceae species interact with self S-RNases (Hua and Kao, 2006; Hua et al., 2007; Kubo et al., 2010; Qiao et al., 2004a; Xu et al., 2013; Yuan et al., 2014). Hua and Kao (2006) revealed that $S^{2}$-SLF1 has a greater affinity for $\mathrm{S}^{3}$-RNases than for self $\mathrm{S}$-RNases, which suggests self-interactions may not be strong enough to induce polyubiquitination of self S-RNases. Interestingly, $S^{2}$-SFBB1 can polyubiquitinate self $\mathrm{S}^{2}$ RNases in vitro, while the polyubiquitination of SRNases by nonself SFBB was not tested (Yuan et al., 2014).

\section{Prunus Pollen $S$ F-Box Proteins Are the Sole Determinants Conferring Incompatibility Reaction Specificity}

Unlike other plants exhibiting S-RNase-based GSI, in which multiple pollen $S$ F-box proteins function as the determining factor, in Prunus species, $S F B$ is the sole pollen $S$ determinant. Furthermore, it has been suggested there are distinct functions for the Prunus pollen $S$ locus. As in other plants, multiple pollen-expressed F-box genes, $S F B$, and three $S$-locus F-box like genes (SLFL1-3), are located at the $S$ locus and its flanking regions in Prunus species (Fig. 3; Entani et al., 2003; Ushijima et al., 2003, 2004). SLFL1, SLFL2, and SLFL3 exhibit a much lower level of allelic sequence polymorphism (i.e., approximately $92.5 \%$ ) than $S F B$ (i.e., 66\%-82.5\%), and there are considerable differences in DNA sequences among the genes (Entani et al., 2003; Matsumoto et al., 2008; Ushijima et al., 2003, 2004). Genetic analyses revealed SLFL1 was highly associated with the $S$ locus, but had undergone some recombination events, while SLFL2 and SLFL3 were not associated with the $S$ locus. This indicates $S F B$ is the only F-box gene located in the Prunus $S$ locus (Entani et al., 2003; Ushijima et al., 2001; Vieira et al., 2008b). The $S$ haplotype with its SLFL1 deleted was also reported to result in normal SI and crosscompatibility, which suggests $S F B$ is the only F-box gene determining the specificity of the SI reaction in 
Prunus species (Matsumoto et al., 2008).

Analyses of naturally occurring and artificially produced SC pollen-part mutant (PPM) $S$ haplotypes indicate $S F B$ is the sole pollen $S$ gene in Prunus species (Tao and Iezzoni, 2010). The first PPM $S$ haplotypes that were characterized at the molecular level were sweet cherry $S^{4^{\prime}}$ and Japanese apricot $S^{f}$, and both were reported to encode a truncated SFB caused by a frameshift mutation (Ushjima et al., 2004). A complete deletion of $S F B$ was later observed in the PPM $S^{3 \prime}$ haplotype of the sweet cherry (Sonneveld et al., 2005). These findings contradict the predicted pollen $S$ gene function in other plants with S-RNase-based GSI, in which the pollen $S$ locus is involved in degrading and detoxifying cytotoxic S-RNases. However, these results may indicate $S F B$ is indispensable for the Prunus SI reaction. Subsequent studies on other SC PPM $S$ haplotypes have confirmed the indispensable role of SFB in SI, and it is now generally accepted that SFB is not necessary for compatible reactions in Prunus species (Hauck et al., 2006a, b; Marchese et al., 2007; Tao et al., 2007; Tsukamoto et al., 2006, 2010; Vilanova et al., 2006; Yamane and Tao, 2009; Yamane et al., 2009). Given that the pollen $S$ gene specifically inhibits everything except self S-RNase, the loss of the pollen $S$ locus should result in self- and cross-incompatibility. Supporting this hypothesis, an SC PPM $S$ haplotype conferred by the loss-of-function mutation of the pollen $S$ locus has never been detected in non-Prunus plant taxa that show S-RNase-based GSI (de Franceschi et al., 2012; Golz et al., 2001; McClure et al., 2011; Meng et al., 2010; Sassa et al., 2009).

A distinct function for SFB has been revealed based on differences between Prunus species and other plants regarding HAP. The tetraploid sour cherry (Prunus cerasus) includes SI and SC individuals. A series of genetic and molecular studies revealed the genotypedependent loss of SI, which requires the accumulation of non-functional $S$ haplotypes (Hauck et al., 2006a, b; Tsukamoto et al., 2006, 2008a, b, 2010). Sour cherry produces diploid pollen, including HAP, and its SI behavior appears to be determined by the one-allelematch model (Fig. 6A; Hauck et al., 2006b). In this model, diploid pollen is rejected when it carries a functional pollen $S$ allele matching its cognate functional $\mathrm{S}-\mathrm{RNase}$ allele in the style. This finding indicates that SFB functions exclusively during incompatible but not compatible reactions, and that the competitive interaction is absent in Prunus species. The possible existence of competitive interactions in Prunus species was recently reported for SC Chinese cherry cultivars (Prunus pseudocerasus L.) (Gu et al., 2013, 2014; Huang et al., 2008). However, these results should be carefully verified because SC in Chinese cherry might be explained by mutations of factors unrelated to the $S$ locus or the accumulation of non-functional $S$ haplotypes (Tao and Iezzoni, 2010; Yu et al., 2010; Zhang et al., 2010).
The distinct SI characteristics of Prunus species are the result of the distinct molecular functions of SFB (Fig. 6B; Tao and Iezzoni, 2010). Phylogenetic analyses of the pollen $S$ F-box genes indicated $S F B$ possesses unique features (Aguiar et al., 2015; Vieira et al., 2009). Prunus SFB has been classified in a separate clade from that containing the Solanaceae, Plantaginaceae, and Maleae pollen $S$ F-box genes (Fig. 7). Greater allelic polymorphisms observed in $S F B$ enabled the characterization of its primary structural features. There are three variable regions in SFB (i.e., Vn, V1, and V2), and two hypervariable regions (i.e., $\mathrm{HVa}$ and $\mathrm{HVb}$; Fig. 6C; Ikeda et al., 2004a; Nunes et al., 2006). Four of the five variable and hypervariable regions are located in the $\mathrm{C}$ terminal region, and may influence allele-specific substrate recognition.

\section{Working Model for Self/Nonself Discrimination in Prunus Species}

Based on what is currently known, the Prunus pollen $S$ F-box protein (i.e., SFB) has been hypothesized to help release the cytotoxic effects of self S-RNases and induce incompatible reactions. In contrast, the pollen $S$ F-box proteins (i.e., SLFs and SFBBs) of other species recognize and detoxify nonself S-RNases to avoid incompatible reactions (Figs. 4B and 6B). To explain the detoxification of Prunus S-RNases, researchers predicted the existence of a hypothetical general inhibitor (GI) that detoxifies S-RNases in compatible pollen tubes (Luu et al., 2001; Tao and Iezzoni, 2010). To characterize the distinct self-recognition molecular mechanism in Prunus species, the biochemical activities of SFB will need to be clarified, and the hypothetical GI should also be identified.

The SFB protein is considered to be part of the SCF complex because the F-box motif is conserved at the $\mathrm{N}$ terminal, and was observed to be under purifying selection (Ikeda et al., 2004a; Nunes et al., 2006). This has been supported by the identification of the functional Skp1-like protein that interacts with SFB (i.e., SSK1). Additionally, the UPS may help regulate SI in Prunus species (Matsumoto et al., 2012). Interestingly, Prunus SSK1 is orthologous to the SSK1 of Solanaceae, Plantaginaceae, and Maleae species, while its pollen $S$ F-box protein partner is phylogenetically remote (Matsumoto et al., 2012; Xu et al., 2013). These facts may indicate that the Prunus pollen $S$ locus has gained different functions in SI recognition from the pollen $S$ loci of other plants during its evolution, despite the shared basal SI molecular components. It is apparent that cytotoxic S-RNase is not the substrate of $\mathrm{SCF}^{\mathrm{SFB}}$ in Prunus species.

Based on the knowledge obtained from other taxa with S-RNase-based GSI, it is possible that E3 ligases that contain a protein orthologous to SLF, SFBB, or SBP1 may be involved in degrading S-RNases. Therefore, Prunus SLFL genes are the best candidates be- 
(A)

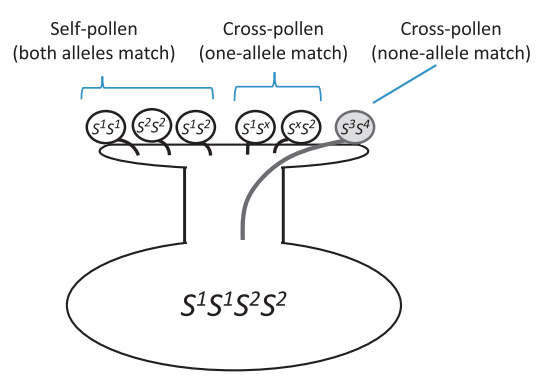

(B)

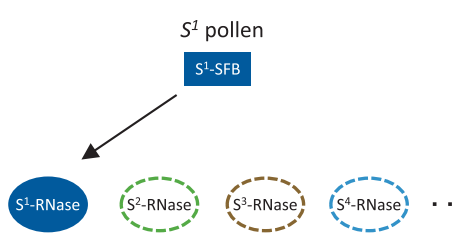

activation of self S-RNase

(C)

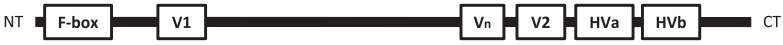

Fig. 6. Putative function of the Prunus pollen $S$ inducing self S-RNase cytotoxicity. (A) Tetraploid Prunus plants are selfincompatible. Heteroallelic pollen is also rejected when one of the $S$ haplotypes in the pollen matches either of the pistil $S$ haplotypes. (B) A single pollen $S$ F-box protein, SFB, is considered to recognize self $\mathrm{S}-\mathrm{RNases}$ and induce their cytotoxic functions. All S-RNases are inhibited unless affected by self SFB. (C) SFB protein structure. F-box: F-box motif; V1, V2, and Vn: variable regions 1,2 , and $\mathrm{n}$; $\mathrm{HVa}$ and $\mathrm{HVb}$ : hypervariable regions a and b; NT: amino-terminus; CT: carboxyl-terminus.

cause phylogenetic studies have highlighted their close relationship with $S F B B$ genes (Fig. 7; Aguiar et al., 2015; de Franceschi et al., 2012; Matsumoto et al., 2008; Morimoto et al., 2015; Sassa et al., 2007, 2009). The SLFLs may help degrade S-RNases in a manner similar to the hypothesized activity of SFBBs. As expected, SLFLs can interact with SSK1, indicating they function as E3 ligases (Matsumoto et al., 2012). Although phylogenetic studies have suggested it is possible, it remains unknown whether any SLFLs function as a GI. The detection of a disrupted SLFL1 gene in a functional self-incompatible $S$ haplotype indicates that SLFL1 is not the only factor necessary for cross compatibility. The most likely GI candidate is SLFL3 because of the SLFL genes, only SLFL3 exhibits upregulated expression during compatible pollination (Habu and Tao, 2013). The Prunus homolog of SBP1 is another candidate for GI. However, the Prunus SBP1 homolog does not appear to interact with S-RNases in vitro (Matsumoto and Tao, 2012a).

One possible explanation for how S-RNase cytotoxicity is controlled by SFBs and GIs to induce SI involves the degradation of the GI by SFB in a selfrecognition-specific manner (i.e., GI degradation model; Fig. 8; Tao and Matsumoto, 2012). All S-

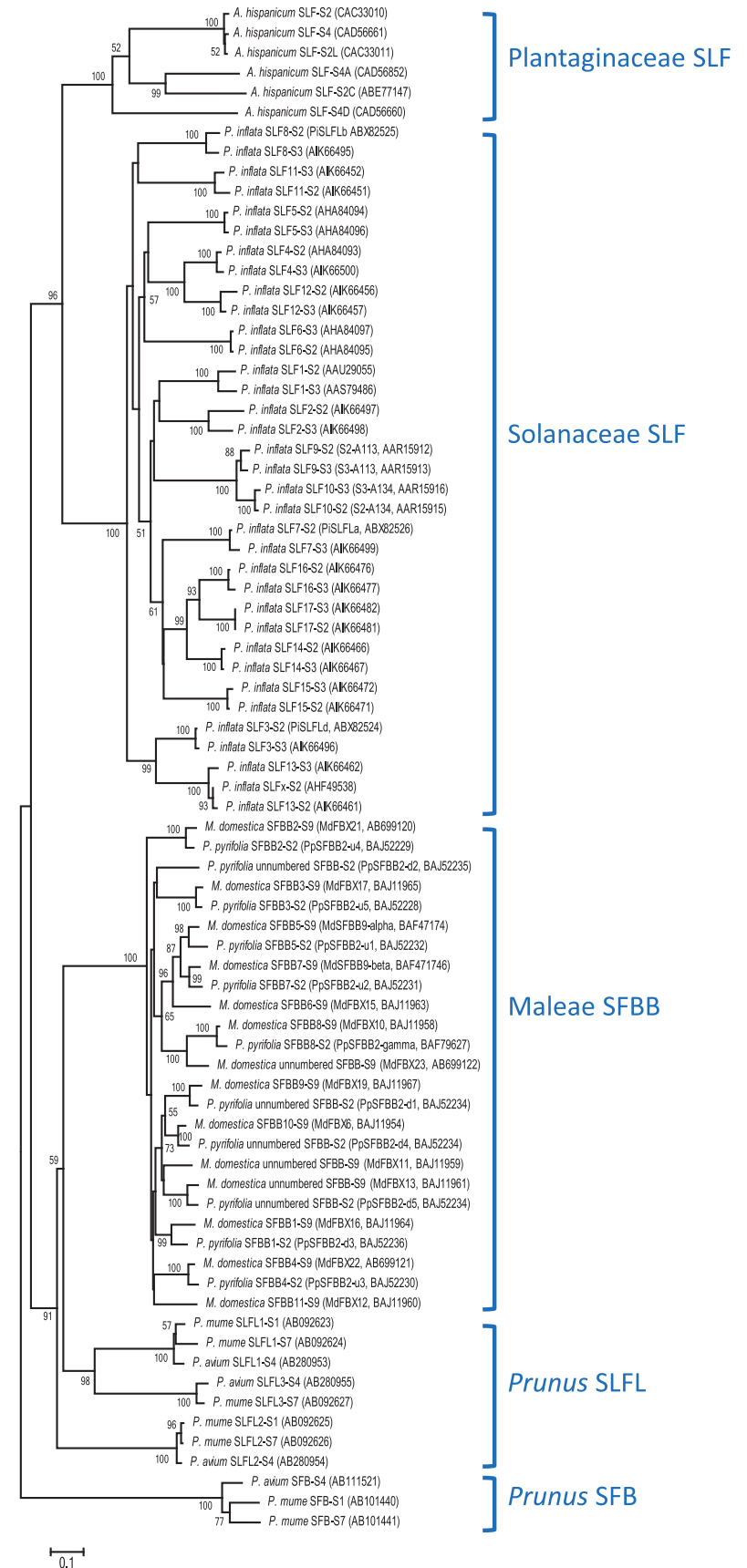

Fig. 7. Neighbor-joining tree constructed using aligned amino acid sequences corresponding to the $S$ locus-linked F-box genes from different taxa exhibiting S-RNase-based gametophytic self-incompatibility. The $S$ locus-linked F-box genes from well characterized $S$ haplotypes in each plant species were chosen to construct the tree. MEGA ver. 6.0 (Tamura et al., 2013) was used to align the amino acid sequences and generate a phylogenetic tree with 1000 bootstrap replicates. Prunus SLFLs clustered with the Maleae SFBBs.

RNases are assumed to be recognized and inhibited by a GI unless they are affected by the cognate SFB. The $\mathrm{SCF}^{\mathrm{SFB}}$ recognizes the complex consisting of self S-RNase and the GI, and polyubiquitinates the GI for degradation to release cytotoxic self S-RNases. In a compatible reaction, the $\mathrm{SCF}^{\mathrm{SFB}}$ would not recognize 
complexes containing nonself S-RNase, which would then be inhibited by a GI. This model is consistent with the Prunus SI characteristics described to date (i.e., self-compatibility conferred by a loss of SFB function, and the absence of competitive interactions in HAP) (Hauck et al., 2006b; Sonneveld et al., 2005; Tsukamoto et al., 2010; Ushijima et al., 2004; Yamane et al., 2003a). However, this hypothesis needs to be carefully verified, which means the GI must be identified.

\section{Self-incompatibility Events That Arrest Self-pollen Tube Growth after Self/Nonself Discrimination}

The molecular mechanism of self/nonself discrimination controlled by specificity determinants is likely different between Prunus species and other plants with SRNase-based GSI. However, self S-RNases commonly avoid being degraded in pollen tubes. The degradation of RNA in incompatible pollen tubes is commonly observed in Nicotiana and Solanum species of the family Solanaceae and in the tribe Maleae of the Rosaceae (Hiratsuka et al., 2007; Liu et al., 2009, 2012; McClure et al., 1990). It remains unclear if an SI reaction cascade caused by self S-RNases varies among different plant taxa.

S-RNase behavior in pollen tubes has been extensively studied in Solanaceae species. It is believed that extracellular S-RNases are non-selectively endocytosed and invade the pollen cytosol similar to other protein toxins or viruses. This is because self/nonself discrimination is assumed to occur in the cytosol of pollen tubes where pollen $S$ F-box proteins are localized (Liu et al., 2014; McClure, 2011; Wang and Xue, 2005). In fact, self and nonself S-RNases are taken in by compatible and incompatible pollen tubes in Solanaceae species (Boivin et al., 2014; Goldraij et al., 2006; Liu et al., 2014; Luu et al., 2000). However, based on microscopic observations, two different models have been proposed to explain how self-discrimination induces SI reactions (Figs. 9 and 10).

In Petunia and Solanum species, S-RNases are distributed in the cytoplasm of compatible and incompatible pollen tubes (Boivin et al., 2014; Liu et al., 2014; Luu et al., 2000). However, investigations involving immunoelectron microscopy revealed that S-RNase abundance decreases in the cytoplasm of compatible pollen tubes, and accumulates in the cytosol of incompatible pollen tubes, $18-24 \mathrm{~h}$ after pollination in Solanum species (Boivin et al., 2014). Additionally, higher GFP expression levels during compatible pollination than during incompatible pollination was observed from $24 \mathrm{~h}$ after pollination in transgenic Solanum plants (Liu et al., 2012). Furthermore, S-RNase uptake by in vitro cultured pollen tubes decreased in Petunia compatible pollen tubes (Liu et al., 2014). Based on these results, we suggest the detoxifi- cation of S-RNases that have non-selectively entered the cytoplasm depends on the degradative activities of pollen $S$ F-box proteins, and the SI reaction is caused by the cytotoxicity of non-degraded and accumulated self S-RNases (i.e., protein degradation model; Fig. 9).

A different scenario has been proposed following a study involving a Nicotiana species (Goldraij et al., 2006). Confocal microscopic analyses identified differences in the localization of S-RNases between compatible and incompatible pollen tubes (Goldraij et al., 2006). First, S-RNases taken in by pollen tubes were sequestered in vacuolar compartments. Later the vacuoles were degraded only in incompatible pollen tubes, which enabled S-RNases to enter the cytoplasm. It was assumed that some of the sequestered S-RNases avoid compartmentalization using an unknown route to participate in self/nonself discrimination. The nondegraded self S-RNases in the cytosol induce the vacuolar breakdown during incompatible pollination. In this scenario, it was assumed that the cytotoxic effects of S-RNases against pollen tubes relied on the compartmentalization controlled by self/nonself discrimination. The SI reaction would be induced by some of the self S-RNases present in the cytosol, and completed by the cytotoxicity of the S-RNases released from vacuoles (i.e., compartmentalization model; Fig. 10). This model is supported by observations of pollinated pistils lacking the stylar-part SI modifier, such as HT-B, $120 \mathrm{~K}$, and the unidentified 4936-factor (Goldraij et al., 2006; Jiménez-Durán et al., 2013; McClure et al., 2011). Down-regulation or mutation of the stylar-part modifiers results in continued vacuolar compartmentalization, which causes SC. Interestingly, the accumulation of sequestered HT-B in pollen vacuoles induces such disruption. The accumulation of HT-B in vacuoles continued in incompatible pollen tubes, while HT-B abundance decreased in the vacuoles of compatible pollen tubes (Goldraij et al., 2006). Another stylar-part SI modifier, StEP, which is a Kunitz-type proteinase inhibitor produced in the stigma and taken up by pollen tubes, is involved in SI by stabilizing HT-B in incompatible pollen tubes (Jiménez-Durán et al., 2013). Vacuolar breakdown is believed to be induced by the inhibition of HTB degradation, which is supposed to be controlled by self-recognition mediated by S-RNases and F-box proteins in the pollen tube cytosol. However, it is unclear whether the SI reaction varies even among Solanaceae species. Interestingly, the suppression of HT-B leads to SC not only in Nicotiana species, but also in Petunia and Solanum species. This suggests there is a common HT-B role during the SI reaction in Solanaceae species, which share the same mechanism (O'Brien et al., 2002; Puerta et al., 2009).

The detection of self S-RNase may induce unknown cytotoxic effects that stimulate early intracellular changes before wide-scale pollen RNA degradation. Additionally, actin organization may be affected by S- 
(A)
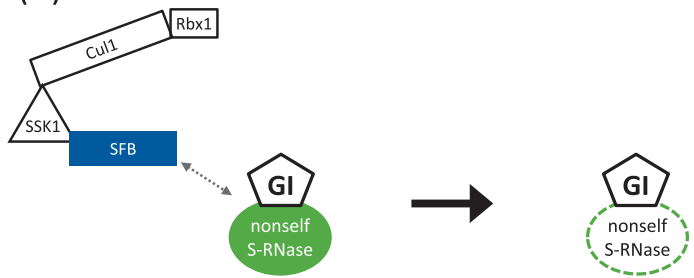

(B)

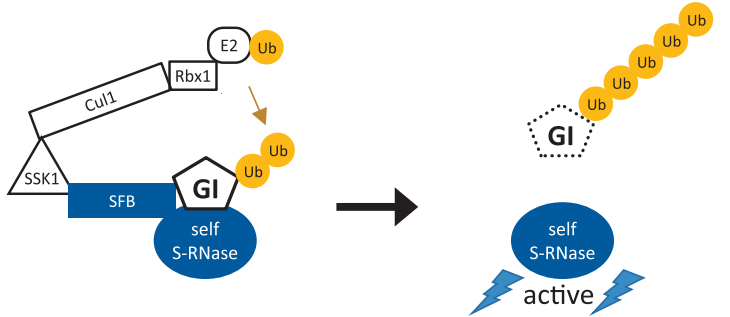

Fig. 8. The molecular basis of Prunus self/nonself discrimination involves the general inhibitor (GI) degradation model, which is based on Prunus pollen $S$ biochemical functions. (A) Nonself S-RNases are thought to be recognized and inhibited by the unidentified GI. The inhibition of nonself S-RNases is believed to be unaffected by SFB. (B) The SFB is assumed to recognize the self S-RNase-GI complex and polyubiquitinate GI. Degradation of the polyubiquitinated GI by the ubiquitin proteasome system leads to the release of active self S-RNases, which enables the incompatibility reaction.

\section{$S^{1}$ pollen tube}

compatible (in $S^{2} S^{3}$ style)

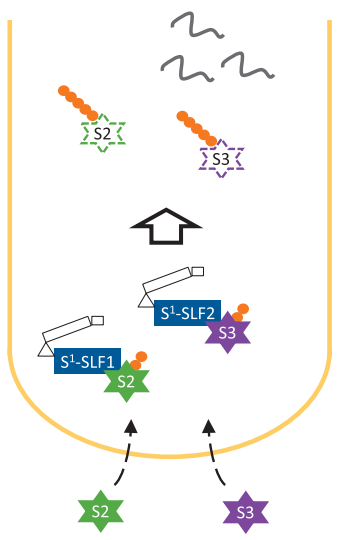

incompatible (in $S^{1} S^{2}$ style)

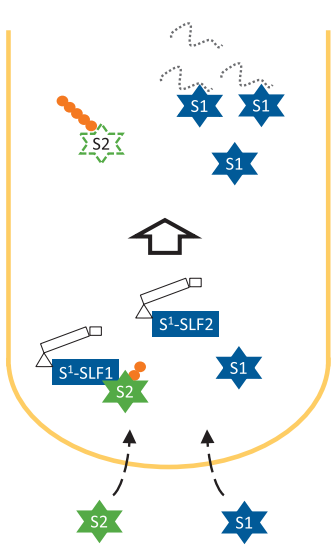

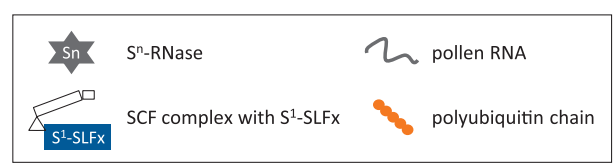

Fig. 9. Degradation model for the incompatibility reaction in pollen tubes. S-RNases non-selectively enter the cytoplasm of pollen tubes growing through the style. Left panel: compatible reaction. S-RNases taken up from nonself $S$ haplotypes are polyubiquitinated by $\mathrm{SCF}^{\mathrm{SLF}}$ and degraded by a proteasome. Right panel: incompatible reaction. Self S-RNases remain active in the pollen cytosol and degrade pollen RNA to elicit cytotoxicity.
$S^{1}$ pollen tube

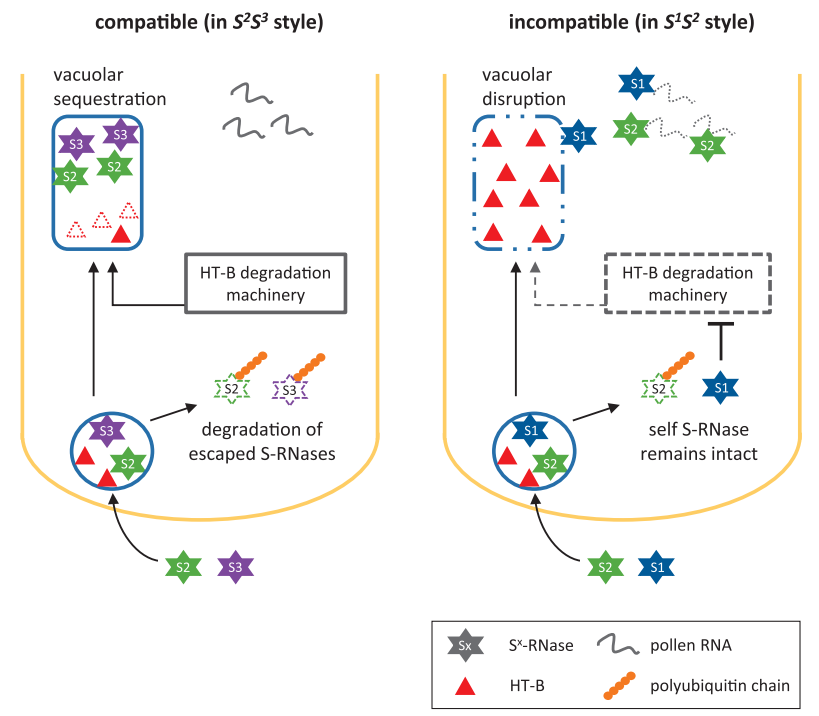

Fig. 10. Compartmentalization model for the incompatibility reaction in pollen tubes. The HT-B and S-RNases are endocytosed by pollen tubes, and sequestered in vacuoles. Some S-RNases enter the cytoplasm from the endosome to participate in self/ nonself discrimination with SLFs. Left panel: compatible reaction. Vacuolar compartmentalization is retained in compatible pollen tubes to circumvent the cytotoxic effects of S-RNases. This compartmentalization is maintained by an unknown HT-B degradation mechanism. Escaped S-RNases are also degraded by SLFs. Right panel: incompatible reaction. Escaped self S-RNases avoid being degraded by SLFs, and are assumed to inhibit HT-B degradation. The accumulation of HT-B disrupts vacuolar compartmentalization to release self and nonself S-RNases, which degrade pollen RNA to elicit cytotoxicity.

RNase cytotoxicity. Incompatible pollen tube growth is inhibited before vacuolar disruption, and F-actin disorganization occurs at the initiation of pollen tube growth inhibition during in vitro and in vivo experiments in Nicotiana species (Roldán et al., 2012, 2015). Delayed Solanum incompatible pollen tube growth occurs within $12 \mathrm{~h}$ of pollination. This is well before the considerable decrease in the synthesis of mRNA and protein, which has been observed once vacuoles are degraded $24 \mathrm{~h}$ after pollination in incompatible pollen tubes (Liu et al., $2012,2014)$. Although there has been no report on the relationship between actin disruption and delayed incompatible pollen tube growth in Solanum species, SRNases were observed to interact with actin through eEF1A, and to be co-localized with actin in incompatible pollen tubes (Soulard et al., 2014).

Our understanding of the SI reaction in the tribe Maleae has recently increased. S-RNase was observed to be non-selectively taken up by in vitro cultured apple pollen tubes. The uptake appeared to be mediated by the cytoskeleton and an $\mathrm{ABC}$ transporter family protein (MdABCF) localized in the pollen tube membrane (Meng et al., 2014a). This ABCF-mediated S-RNaseuptake pathway was also required for SI in Petunia species. In pollen tubes, S-RNases were initially localized 
in vesicles, but then migrated into the cytoplasm to induce cytoskeletal disorganization, possibly through interactions with the specific apple Rho-like GTPase homolog (MdROP8; Meng et al., 2014b, c). The cytoskeletal disorganization may contribute to the delayed self-pollen tube growth during the early stages. Programmed cell death eventually inhibited self-pollen tube growth (Liu et al., 2007; Wang et al., 2009, 2010). Disturbance in generation of reactive oxygen species in incompatible pollen tubes is expected to lead to cytoskeletal disruption, mitochondrial collapse, and DNA fragmentation. Higher transglutaminase activity in incompatibly pollinated apple styles, in which proteins, including cytoskeletal components, may be modified by the crosslinking of polyamines to form high molecular weight aggregates, may lead to programmed cell death (del Duca et al., 2010).

Only a few studies have examined the intracellular SI events in Prunus species. In the early electron microscopy analyses by Uwate and Lin (1980), no obvious structural differences were observed between compatible and incompatible pollen tubes $6 \mathrm{~h}$ after pollination. Cytoskeletal changes may be involved in the Prunus SI reaction because the artificially reduced S-RNases (in a reducing intracellular environment) interact with actin in vitro (Matsumoto and Tao, 2012b). Habu and Tao (2013) recently identified thousands of genes differentially regulated between self- and cross-pollinated pistils using next-generation sequencing technologies. Interestingly, no homologs of the solanaceous pistil factors, such as HT-B or $120 \mathrm{~K}$, were detected, indicating there is a distinct Prunus SI reaction. A pollen-part non$S$ determinant (i.e., pollen modifier) may be important for elucidating some aspects of the Prunus SI reaction (Vilanova et al., 2006; Wünsch and Hormaza, 2004; Wünsch et al., 2010). In several sweet cherry and apricot cultivars, a mutated pollen modifier conferred SC without affecting $S F B$ expression. Interestingly, the modifier loci of sweet cherry and apricot cultivars were located at the distal end of linkage group 3 ( $M$ locus), which is the syntenic region of the Maleae $S$ locus (Cachi and Wünsch, 2011, 2014; Zuriaga et al., 2012, 2013). However, none of genes reported to be involved in SI are located in this region (Habu and Tao, 2013; Zuriaga et al., 2012). Identifying the pollen modifier gene will provide new insights into the Prunus-specific SI mechanism. Undoubtedly, further research is required to fully elucidate Prunus self/nonselfrecognition, with a particular need for a histochemical analysis of the Prunus SI system.

\section{Conclusion and Perspectives}

Studies during the last decade have suggested the recognition mechanisms of the S-RNase-based GSI mechanism in Prunus are different from those of other taxa, including the families Solanaceae and Plantaginaceae and the tribe Maleae from the family
Rosaceae. There have been no findings that contradict the hypothesis that Prunus S-RNases have cytotoxic effects similar to the expected activities of S-RNases in other plants that exhibit S-RNase-based GSI. However, there is considerable evidence indicating the Prunus pollen $S$ F-box protein may function differently than the corresponding proteins in other plants. Prunus SFB is believed to specifically recognize self S-RNases to induce their cytotoxicity, while the pollen $S$ F-box proteins of other plants detoxify nonself S-RNases. In Prunus species, the GI is believed to detoxify all SRNases. Recent biochemical and phylogenetic studies on SFB revealed several GI candidates, and provide important information regarding the distinct selfrecognition mechanism in Prunus species. We expect that the molecular mechanism controlling Prunus SI will be fully elucidated in the near future, enabling the regulation of Prunus SI.

\section{Literature Cited}

Adachi, Y., S. Komori, Y. Hoshikawa, N. Tanaka, K. Abe, H. Bessho, M. Watanabe and A. Suzuki. 2009. Characteristics of fruiting and pollen tube growth of apple autotetraploid cultivars showing self-compatibility. J. Japan. Soc. Hort. Sci. 78: 402-409.

Aguiar, B., J. Vieira, A. E. Cunha, N. A. Fonseca, A. Iezzoni, S. van Nocker and C. P. Vieira. 2015. Convergent Evolution at the gametophytic self-incompatibility system in Malus and Prunus. PLoS ONE 10: e0126138.

Aguiar, B., J. Vieira, A. E. Cunha, N. A. Fonseca, D. ReboiroJato, M. Reboiro-Jato, F. Fdez-Riverola, O. Raspé and C. P. Vieira. 2013. Patterns of evolution at the gametophytic selfincompatibility Sorbus aucuparia (Pyrinae) $S$ pollen genes support the non-self recognition by multiple factors model. J. Exp. Bot. 64: 2423-2434.

Anderson, M. A., E. C. Cornish, S. L. Mau, E. G. Williams, R. Hoggart, A. Atkinson, I. Bönig, B. Grego, R. Simpson, P. J. Roche, J. D. Haley, J. D. Penschow, H. D. Niall, G. W. Tregear, J. P. Coghlan, R. J. Crawford and A. E. Clarke. 1986. Cloning of cDNA for a stylar glycoprotein associated with expression of self-incompatibility in Nicotiana alata. Nature 321: 38-44

Anderson, M. A., G. I. McFadden, R. Bernatzky, A. Atkinson, T. Orpin, H. Dedman, G. W. Tregear, R. Fernlyey and A. E. Clarke. 1989. Sequence variability of three alleles of the self-incompatibility gene of Nicotiana alata. Plant Cell 1: 483-491.

Asquini, E., M. Gerdol, D. Gasperini, B. Igic, G. Graziosi and A. Pallavicini. 2011. S-RNase-like sequences in styles of Coffea (Rubiaceae). Evidence for S-RNase based gametophytic self-incompatibility? Tropical Plant Biol. 4: 237-249.

Beppu, K., Y. Takemoto, H. Yamane, H. Yaegaki, M. Yamaguchi, I. Kataoka and R. Tao. 2003. Determination of $S$-haplotypes of Japanese plum (Prunus salicina Lindl.) cultivars by PCR and cross-pollination tests. J. Hort. Sci. Biotech. 78: 315318.

Boivin, N., D. Morse and M. Cappadocia. 2014. Degradation of S-RNase in compatible pollen tubes of Solanum chacoense inferred by immunogold labeling. J. Cell Sci. 127: 41234127.

Brootharerts, W., G. A. Janssens, P. Proost and W. F. Broekaert. 1995. cDNA cloning and molecular analysis of two selfincompatibility alleles from apples. Plant Mol. Biol. 21: 
499-511.

Brootharerts, W., J. Keulemans and I. V. Nerum. 2004. Self-fertile apple resulting from S-RNase gene silencing. Plant Cell Rep. 22: 497-501.

Cachi, A. M. and A. Wünsch. 2011. Characterization and mapping of non- $S$ gametophytic self-compatibility in sweet cherry (Prunus avium L.). J. Exp. Bot. 62: 1847-1856.

Cachi, A. M. and A. Wünsch. 2014. Characterization of selfcompatibility in sweet cherry varieties by crossing experiments and molecular genetic analysis. Tree Genet. Genomes 10: $1205-1212$.

Carrera, L., J. Sanzol, M. Herrero and J. I. Hormaza. 2009. Genomic characterization of self-incompatibility ribonucleases (S-RNases) in loquat (Eriobotrya japonica Lindl.) (Rosaceae, Pyrinae). Mol. Breed. 23: 539-551.

Certal, A. C., A. M. Sanchez, H. Kokko, W. Broothaerts, M. M. Olivieira and J. A. Feijó. 1999. S-RNases in apple are expressed in the pistil along the pollen tube growth path. Sex. Plant Reprod. 12: 94-98.

Chen, G., B. Zhang, L. Liu, Q. Li, Y. Zhang, Q. Xie and Y. Xue. 2012. Identification of a ubiquitin-binding structure in Slocus F-box protein controlling S-RNase-based selfincompatibility. J. Genet. Gen. 39: 93-102.

de Franceschi, P., L. Dondini and J. Sanzol. 2012. Molecular bases and evolutionary dynamics of self-incompatibility in the Pyrinae (Rosaceae). J. Exp. Bot. 63: 4015-4032.

de Franceschi, P., L. Pierantoni, L. Dondini, M. Grandi, J. Sanzol and S. Sansavini. 2011. Cloning and mapping multiple Slocus F-box genes in European pear (Pyrus communis L.). Tree Genet. Genomes 7: 231-240.

del Duca, S., G. Cai, A. Di Sandro and D. Serafini-Fracassini. 2010. Compatible and self-incompatible pollination in Pyrus communis displays different polyamine levels and transglutaminase activity. Amino Acids 38: 659-667.

de Nettancourt, D. 2001. Incompability and incongruity in wild and cultivated plants. Springer, Berlin.

Deshaies, R. J. and C. A. P. Joazeiro. 2009. RING domain E3 ubiquitin ligases. Annu. Rev. Biochem. 78: 399-434.

Entani, T., M. Iwano, H. Shiba, F. S. Che, A. Isogai and S. Takayama. 2003. Comparative analysis of the selfincompatibility $(S)$ locus region of Prunus mume: identification of a pollen-expressed F-box gene with allelic diversity. Genes Cells 8: 203-213.

Entani, T., M. Iwano, H. Shiba, S. Takayama, K. Fukui and A. Isogai. 1999a. Centromeric localization of an S-RNase gene in Petunia hybrida Vilm. Theor. Appl. Genet. 99: 391-397.

Entani, T., K. Kubo, S. Isogai, Y. Fukao, M. Shirakawa, A. Isogai and S. Takayama. 2014. Ubiquitin-proteasome-mediated degradation of S-RNase in a solanaceous cross-compatibility reaction. Plant J. 78: 1014-1021.

Entani, T., S. Takayama, M. Iwano, H. Shiba, F. S. Che and A. Isogai. 1999b. Relationship between polyploidy and pollen self-incompatibility phenotype in Petunia hybrida Vilm. Biosci. Biotechnol. Biochem. 63: 1882-1888.

Goldraij, A., K. Kondo, C. B. Lee, C. N. Hancock, M. Sivaguru, S. Vazquez-Santana, S. Kim, T. E. Phillips, F. Cruz-Garcia and B. A. McClure. 2006. Compartmentalization of S-RNase and HT-B degradation in self-incompatible Nicotiana. Nature 439: 805-810.

Golz, J. F., H. Y. Oh, V. Su, M. Kusaba and E. Newbigin. 2001. Genetics analysis of Nicotiana pollen-part mutants is consistent with the presence of an S-ribonuclease inhibitor at the $S$ locus. Proc. Natl. Acad. Sci. USA 98: 15372-15376.

Golz, J. F., V. Su, A. E. Clarke and E. Newbigin. 1999. A molecular description of mutations affecting the pollen components of the Nicotiana alata $S$ locus. Genetics 152: 1123-1135.
Gu, C., Q. Liu, M. A. Khan, J. Wu and S. Zhang. 2014. Heterodiploid pollen grains that represent self-compatibility are incompatible with non-self-receptors in tetraploid Chinese cherry (Prunus pseudocerasus Lindl). Tree Genet. Genomes 10: 619-625.

Gu, C., Q. Liu, Y. Yang, S. Zhang, M. A. Khan, J. Wu and S. Zhang. 2013. Inheritance of hetero-diploid pollen $S$ haplotype in self-compatible tetraploid Chinese cherry (Prunus pseudocerasus Lindl). PLoS ONE 8: e61219.

Habu, T. and R. Tao. 2013. Transcriptome analysis of self- and cross-pollinated pistils of Japanese apricot (Prunus mume Sieb et Zucc.). J. Japan. Soc. Hort. Sci. 83: 95-107.

Habu, T., D. Matsumoto, K. Fukuta, R. Tao, H. Yaegaki, M. Yamaguchi, M. Matsuda, T. Konishi, A. Kitajima and T. Yamada. 2008. Cloning and characterization of twelve $S$ RNase alleles in Jaoanese apricot (Prunus mume Sieb et Zucc.). J. Japan. Soc. Hort. Sci. 77: 374-381.

Hanada, T., K. Fukakuta, H. Yamane, T. Esumi, R. Tao, T. M. Gradziel, A. M. Dandekar, M. A. Fernández, J. M. Alonso and R. Socias i Company. 2009. Cloning and characterization of a self-compatible $S^{f}$ haplotype in almond [Prunus dulcis (Mill.) D.A. Webb. syn. P.amygdalus Batsch] to resolve previous confusion in its $S^{\prime}$-RNase sequence. HortScience 44: 609-613.

Hauck, N. R., K. Ikeda, R. Tao and A. F. Iezzoni. 2006a. The mutated $S_{I}$-haplotype in sour cherry has an altered $S$-haplotype specific F-box protein gene. J. Hered. 97: 514-520.

Hauck, N. R., H. Yamane, R. Tao and A. F. Iezzoni. 2006b. Accumulation of non-functional $S$-haplotypes results in the breakdown of gametophytic self-incompatibility in tetraploid Prunus. Genetics 172: 1191-1198.

Hiratsuka, S., A. Hirano and S. Zhang. 2007. Comparison of S-RNase, RNase $T_{1}, T_{2}$, and A effects on growth inhibition and RNA degradation of in vitro-cultures pear pollen. Sci. Hortic. 114: 159-163.

Hua, Z. and T. Kao. 2006. Identification and characterization of components of a putative Petunia S-locus F-box-containing E3 ligase complex involved in S-RNase-based selfincompatibility. Plant Cell 18: 2531-2553.

Hua, Z. and T. Kao. 2008. Identification of major lysine residues of $\mathrm{S}_{3}$-RNase of Petunia inflata involved in ubiquitin-26S proteasome mediated degradation in vitro. Plant J. 54: 10941104.

Hua, Z., X. Meng and T. Kao. 2007. Comparison of Petunia inflata S-Locus F-box protein (Pi SLF) with Pi SLF like proteins reveals its unique function in S-RNase based selfincompatibility. Plant Cell 19: 3593-3609.

Huang, S., H. S. Lee, B. Karunanandaa and T. Kao. 1994. Ribonuclease activity of Petunia inflata S proteins is essential for rejection of self-pollen. Plant Cell 6: 1021-1028.

Huang, S., H. Wu, Y. Li, J. Wu, S. Zhang, W. Heng and S. Zhang. 2008. Competitive interaction between two functional Shaplotypes confer self-compatibility on tetraploid Chinese cherry (Prunus pseudocerasus Lindl. CV. Nanjing Chuisi). Plant Cell Rep. 27: 1075-1085.

Huang, J., L. Zhao, Q. Yang and Y. Xue. 2006. AhSSK1, a novel SKP1-like protein that interacts with the S-locus F-box protein SLF. Plant J. 46: 780-793.

Ida, K., S. Norioka, M. Yamamoto, T. Kumasaka, E. Yamashita, E. newbigin, A. E. Clarke, F. Sakiyama and M. Sato. 2001. The $1.55 \AA$ resolution structure of Nicotiana alata $S_{\mathrm{F} 11^{-}}$ RNase associated with gametophytic self-incompatibility. J. Mol. Biol. 314: 103-112.

Igic, B. and J. R. Kohn. 2001. Evolutionary relationships among self-incompatibility RNases. Proc. Natl. Acad. Sci. USA 98: 13167-13171. 
Ikeda, K., B. Igic, K. Ushijima, H. Yamane, N. R. Hauck, R. Nakano, H. Sassa, A. F. Iezzoni, J. R. Kohn and R. Tao. 2004a. Primary structural features of the $S$ haplotypespecific F-box protein, SFB, in Prunus. Sex. Plant Reprod. 16: 235-243.

Ikeda, K., A. Watari, K. Ushijima, H. Yamane, N. R. Hauck, A. F. Iezzoni and R. Tao. 2004b. Molecular markers for the selfcompatible $S^{4^{\prime}}$-haplotype, a pollen-part mutant in sweet cherry (Prunus avium L.) J. Amer. Soc. Hort. Sci. 129: 724-728.

Ioerger, T. R., J. R. Gohlke, B. Xu and T. Kao. 1991. Primary structural features of the self-incompatibility protein in Solananceae. Sex. Plant Reprod. 4: 81-87.

Ishimizu, T., T. Shinkawa, F. Sakiyama and S. Norioka. 1998. Primary structural features of rosaceous S-RNases associated with gametophytic self-incompatibility. Plant Mol. Biol. 37: 931-941.

Iwano, M. and S. Takayama. 2012. Self/non-self discrimination in angiosperm self-incompatibility. Curr. Opin. Plant Biol. 15: 78-83.

Jiménez-Durán, K., B. McClure, F. García-Campusano, R. Rodríguez-Sotres, J. Cisneros, G. Busot and F. Cruz-García. 2013. NaSTEP: a proteinase inhibitor essential to selfincompatibility and a positive regulator of HT-B stability in Nicotiana alata pollen tubes. Plant Physiol. 161: 97-107.

Kakui, H., M. Kato, K. Ushijima, M. Kitaguchi, S. Kato and H. Sassa. 2011. Sequence divergence and loss-of-function phenotypes of $S$ locus F-box brothers (SFBB) genes are consistent with non-self recognition by multiple pollen determinants in self-incompatibility of Japanese pear (Pyrus pyrifolia). Plant J. 68: 1028-1038.

Kao, T. and A. G. McCubbin. 1996. How flowering plants discriminate between self and non-self pollen to prevent inbreeding. Proc. Natl. Acad. Sci. USA 93: 12059-12065.

Karunanandaa, B., S. Huang and T. Kao. 1994. Carbohydrate moiety of the Petunia inflata $\mathrm{S}_{3}$ protein is not required for self-incompatiblility interactions between pollen and pistil. Plant Cell 6: 1933-1940.

Kowyama, Y., C. Kunz, I. Lewis, E. Newbigin, A. E. Clarke and M. A. Anderson. 1994. Self-incompatibility in a Lycopersicon peruvianum variant (LA2157) is associated with a lack of style S-RNase activity. Theor. Appl. Genet. 88: 859-864.

Kubo, K., T. Entani, A. Tanaka, N. Wang, A. M. Fields, Z. Hua, M. Toyoda, S. Kawashima, T. Ando, A. Isogai, T. Kao and S. Takayama. 2010. Collaborative non-self recognition system in S-RNase-based self-incompatibility. Science 330: 796-799.

Kubo, K., T. Paape, M. Hatakeyama, T. Entani, A. Takara, K. Kajihara, M. Tsukahara, R. Shimizu-Inatsugi, K. K. Shimizu and S. Takayama. 2015. Gene duplication and genetic exchange drive the evolution of S-RNase-based selfincompatibility in Petunia. Nature Plant 1: 14005.

Lai, Z., W. Ma, B. Han, L. Liang, Y. Zhang, G. Hong and Y. Xue. 2002. An F-box gene linked to the self-incompatibility $(S)$ locus of Antirrhinum is expressed specifically in pollen and tapetum. Plant Mol. Biol. 50: 289-296.

Lee, H. S., S. Huang and T. Kao. 1994. S proteins control rejection of incompatible pollen in Petunia inflata. Nature 367: $560-563$.

Lewis, D. and I. Modilbowska. 1942. Genetical studies in pears. Pollen-tube growth and incompatibility. J. Genet. 43: 211222.

Li, W. and R. T. Chetlat. 2014. The role of a pollen-expressed cullin1 protein in gametophytophytic self-incompatibility. Genetics 196: 439-442.

Li, S., P. Sun, J. S. Williams and T. Kao. 2014. Identification of the self-incompatibility locus F-box protein-containing complex in Petunia inflata. Plant Reprod. 27: 31-45.

Liu, B., N. Boivin, D. Morse and M. Cappadocia. 2012. A time course of GFP expression and mRNA stability in pollen tubes following compatible and incompatible pollinations in Solanum chacoense. Sex. Plant Reprod. 25: 205-213.

Liu, W., J. Fan, J. Li, Y. Song, Q. Li, Y. Zhang and Y. Xue. 2014. $\mathrm{SCF}^{\mathrm{SLF}}$-mediated cytosolic degradation of S-RNase is required for cross-pollen compatibility in S-RNase-based selfincompatibility in Petunia hybrida. Front. Genet. 5: 228.

Liu, B., D. Morse and M. Cappadocia. 2008. Glycosylation of SRNase may influence pollen rejection thresholds in Solanum chacoense. J. Exp. Bot. 59: 545-552.

Liu, B., D. Morse and M. Cappadocia. 2009. Compatible pollination in Solanum chacoense decrease both S-RNase and SRNase mRNA. PLoS ONE 4: e5774.

Liu, Z., G. Xu and S. Zhang. 2007. Pyrus pyrifolia stylar SRNase induces alterations in the actin cytoskeleton in selfpollen and tubes in vitro. Protoplasma 232: 61-67.

Luu, D. T., X. Qin, G. Laublin, Q. Yang, D. Morse and M. Cappadocia. 2001. Rejection of $S$-heteroallelic pollen by a dual-specific S-RNase in Solanum chacoense predicts a multimeric SI pollen component. Genetics 159: 329-335.

Luu, D. T., X. Qin, D. Morse and M. Cappadocia. 2000. S-RNase uptake by compatible pollen tubes in gametophytic selfincompatibility. Nature 407: 649-651.

Marchese, A., R. I. Bošković, T. Caruso, A. Raimondo, M. Cutuli and K. R. Tobutt. 2007. A new self-compatibility haplotype in the sweet cherry 'Kronio', $S_{5}$ ', attributable to a pollen-part mutation in the $S F B$ gene. J. Exp. Bot. 58: 4347-4356.

Mase, N., Y. Sawamura, T. Yamamoto, N. Takada, S. Nishio, T. Saito and H. Iketani. 2014. A segmental duplication encompassing $S$-haplotype triggers pollen-part self-compatibility in Japanese pear (Pyrus pyrifolia). Mol. Breed. 33: 117-128.

Matsumoto, D. and R. Tao. 2012a. Yeast two-hybrid screening for the general inhibitor detoxifying S-RNase in Prunus. Acta Hortic. 967: 167-170.

Matsumoto, D. and R. Tao. 2012b. Isolation of pollen-expressed actin as a candidate protein interacting with S-RNase in Prunus avium L. J. Japan. Soc. Hort. Sci. 81: 41-47.

Matsumoto, S., K. Yamada, K. Shiratake, K. Okada and K. Abe. 2010. Structural and functional analysis of two new S-RNase alleles, Ssi5 and Sad5, in apple. J. Hort. Sci. Biotech. 85: 131-136.

Matsumoto, D., H. Yamane, K. Abe and R. Tao. 2012. Identification of a Skp1-like protein interacting with SFB, the pollen $S$ determinant of the gametophytic self-incompatibility in Prunus. Plant Physiol. 159: 1252-1262.

Matsumoto, D., H. Yamane and R. Tao. 2008. Characterization of SLFL1, a pollen-expressed F-box gene in the Prunus $S$ locus. Sex. Plant Reprod. 21: 113-121.

Matton, D. P., O. Maes, G. Laublin, Q. Xike, C. Bertrand, D. Morse and M. Cappadocia. 1997. Hypervariable domains of self-incompatibility RNase mediate allele-specific pollen recognition. Plant Cell. 9: 1757-1766.

McClure, B. A., F. Cruz-Garcia and C. Romero. 2011. Compatibility and incompatibility in S-RNase-based systems. Ann. Bot. 108: 647-658.

McClure, B. A., J. E. Gray, M. A. Anderson and A. E. Clarke. 1990. Self-incompatibility in Nicotiana alata involves degradation of pollen RNA. Nature 347: 757-760.

McClure, B. A., V. Haring, P. R. Ebert, M. A. Anderson, R. J. Simpson, F. Sakiyama and A. E. Clarke. 1989. Style selfincompatibility gene products of Nicotiana alata are ribonucleases. Nature 342: 955-957.

McNeill, J., F. R. Barrie, W. R. Buck, V. Dmoulin, W. Greuter, 
D. L. Hawksworth, P. S. Herendeen, S. Knapp, K. Marhold, J. Prado, W. F. Prud'Homme Van Reine, G. F. Smith, J. H. Wiersema and N. J. Turland. 2012. International Code of Nomenclature for Algae, Fungi, and Plants (Melbourne Code) 2012. Koeltz Scientific Books, Germany.

Meng, D., Z. Gu, W. Li, A. Wang, H. Yuan, Q. Yang and T. Li. 2014a. Apple MdABCF assists in the transporation of $S$ RNase into pollen tubes. Plant J. 78: 990-1002.

Meng, D., Z. Gu, A. Wang, H. Yuan, Q. Yang, X. Duan and T. Li. 2014c. Screening and characterization of apple Rho-like GTPase (MdROPs) genes related to S-Rnase mediated selfincompatibility. Plant Cell Tiss. Organ Cult. 117: 465-476.

Meng, D., Z. Gu, H. Yuan, A. Wang, W. Li, Q. Yang, Y. Zhu and T. Li. 2014b. The microtubule cytoskeleton and pollen tube Golgi vesicle system are required for in vitro $S$-RNase internalization and gametophytic self-incompatibility in apple. Plant Cell Physiol. 55: 977-989.

Meng, X., P. Sun and T. Kao. 2010. S-RNase-based selfincompatibility in Petunia inflata. Ann. Bot. 108: 637-646.

Minamikawa, M., D. Fujii, H. Kakui, N. Kotoda and H. Sassa. 2013. Identification of an S-RNase binding protein 1 (SBP1) homolog of apple (Malus $\times$ domestica). Plant Biotechnol. 30: 119-123.

Minamikawa, M., H. Kakui, S. Wang, N. Kotoda, S. Kikuchi, T. Koba and H. Sassa. 2010. Apple $S$ locus region represents a large cluster of related, polymorphic and pollen-specific Fbox genes. Plant Mol. Biol. 74: 143-154.

Minamikawa, M. F., R. Koyano, S. Kikuchi, T. Koba and H. Sassa. 2014. Identification of SFBB-containing canonical and noncanonical SCF complexes in pollen of apple (Malus $\times$ domestica). PLoS ONE 9: e97642.

Morimoto, T., T. Akagi and R. Tao. 2015. Evolutionary analysis of genes for S-RNase-based self-incompatibility reveals $S$ locus duplications in ancestral Rosaceae. Hort. J. 84: 233242.

Murfett, J., T. L. Atherton, B. Mou, C. S. Gasser and B. A. McClure. 1994. S-RNase expressed in transgenic Nicotiana causes $S$-allele-specific pollen rejection. Nature 367: 563566.

Nowak, M. D., A. P. Davis, F. Anthony and A. D. Yoder. 2011. Expression and trans-specific polymorphism of selfincompatibility RNases in Coffeae (Rubiaceae). PLoS ONE 6: e21019.

Nunes, M. D. S., R. A. M. Santos, S. M. Ferreira, J. Vieira and C. P. Vieira. 2006. Variability patterns and positively selected sites at the gametophytic self-incompatibility pollen $S F B$ gene in a wild self-incompatible Prunus spinosa (Rosaceae) population. New Phytol. 172: 577-587.

Nyska, R., A. Raz, Z. Baras, S. Shafir, M. Goldway and D. Schneider. 2013. Self-compatibility in loquat (Eriobotrya japonica Lindl.) is possibly due to S6-RNase mutation. Sci. Hortic. 161: 43-48.

O'Brien, M., C. Kapfer, G. Major, M. Laurin, C. Bertrand, K. Kondo, Y. Kowyama and D. P. Matton. 2002. Molecular analysis of the stylar-expressed Solanum chacoense small asparagine-rich protein family related to the HT modifier of gametophytic self-incompatibility in Nicotiana. Plant J. 32: 985-996.

Okada, K., S. Moriya, T. Haji and K. Abe. 2013. Isolation and characterization of multiple F-box genes linked to the $S_{9}$ and $S_{10}$-RNase in apple (Malus $\times$ domestica Borkh.). Plant Reprod. 26: 101-111.

Okada, K., N. Tonaka, Y. Moriya, N. Norioka, Y. Sawamura, T. Matsumoto, T. Nakanishi and T. Takasaki-Yasuda. 2008. Deletion of a $236 \mathrm{~kb}$ region around $S_{4}$-RNase in a stylar-part mutant $S_{4}^{S M}$-haplotype of Japanese pear. Plant Mol. Biol. 66:
389-400.

Okada, K., N. Tonaka, T. Taguchi, T. Ichikawa, Y. Sawamura, T. Nakanishi and T. Takasaki-Yasuda. 2010. Related polymorphic F-box protein genes between haplotypes clustering in the BAC coting sequences around the $S$-RNase of Japanese pear. J. Exp. Bot. 62: 1887-1902.

Ortega, E., R. I. Bošković, D. J. Sargent and K. R. Tobutt. 2006. Analysis of S-RNases alleles of almond (Prunus dulcis): characterization of new sequences, resolution of synonyms and evidence of intragenic recombination. Mol. Gen. Genet. 276: 413-426.

Potter, D., T. Eriksson, R. C. Evans, S. Oh, J. E. E. Smedmark, D. R. Morgan, M. Kerr, K. R. Robertson, M. Arsenault, T. A. Dickinson and C. S. Campbell. 2007. Phylogenetic classification of Rosaceae. Plant Syst. Evol. 266: 5-43.

Puerta, A. R., K. Ushijima, T. Koba and H. Sassa. 2009. Identification and functional analysis of pistil self-incompatibility factor HT-B of Petunia. J. Exp. Bot. 60: 1309-1318.

Qi, Y., H. Wu, Y. Cao, J. Wu, S. Tao and S. Zhang. 2011. Heteroallelic diploid pollen led to self-compatibility in tetraploid cultivcar 'Sha 01' (Pyrus sinkiangensis Yü). Tree Genet. Genomes 7: 685-695.

Qiao, H., H. Wang, L. Zhao, J. Zhou, J. Huang, Y. Zhang and Y. Xue. 2004a. The F-box protein AhSLF-S 2 physically interacts with S-RNases that may be inhibited by the ubiquitin/26S proteasome pathway of protein degradation during compatible pollination in Antirrhinum. Plant Cell 16: 582-595.

Qiao, H., F. Wang, L. Zhao, J. Zhou, Z. Lai, Y. Zhang, T. P. Robbins and Y. Xue. 2004b. The F-box protein AhSLF-S controls the pollen function of S-RNase-based selfincompatibility. Plant Cell 16: 2307-2322.

Qin, X., J. Soulard, G. Laublin, D. Morse and M. Cappadocia. 2005. Molecular analysis of the conserved $\mathrm{C} 4$ region of the $\mathrm{S}_{11}$-RNase of Solanum chacoense. Planta 221: 531-537.

Raspé, O. and J. R. Kohn. 2002. S-allele diversity in Sorbus aucuparia and Crataegus monogyna (Rosaceae: Maloideae). Heredity 88: 458-465.

Roldán, J. A., H. J. Rojas and A. Goldraij. 2012. Disorganization of F-actin cytoskeleton precedes vacuolar disruption in pollen tubes during in vivo self-incompatibility response in Nicotiana alata. Ann. Bot. 110: 787-795.

Roldán, J. A., H. J. Rojas and A. Goldraij. 2015. In vitro inhibition of incompatible pollen tubes in Nicotiana alata involves the uncoupling of the F-actin cytoskeleton and the endomembrane trafficking system. Protoplasma 252: 63-75.

Saito, T., Y. Sato, Y. Sawamura, M. Shoda, T. Takasaki-Yasuda and K. Kotobuki. 2012. Dual recognition of $S_{1}$ and $S_{4}$ pistils by $S_{4}^{s m}$ pollen in self-incompatibility of Japanese pear (Pyrus pyrifolia Nakai). Tree Genet. Genomes 8: 689-694.

Sanzol, J. 2009. Pistil-function breakdown in a new $S$-allele of European pear, $S_{21}{ }^{\mathrm{O}}$, confers self-compatibility. Plant Cell Rep. 28: 457-467.

Sassa, H., H. Hirano and H. Ikehashi. 1992. Self-incompatibilityrelated RNases in styles of Japanse pear (Pyrus serotina Rehd.). Plant Cell Physiol. 33: 811-814.

Sassa, H., H. Hirano and H. Ikehashi. 1993. Identification and characterization of stylar glycoproteins associated with selfincompatibility genes of Japanese pear, Pyrus serotina Rehd. Mol. Gen. Genet. 241: 17-25.

Sassa, H., H. Hirano, T. Nishio and T. Koba. 1997. Style-specific self-compatible mutation caused by deletion of the S-RNase gene in Japanese pear (Pyrus serotina). Plant J. 12: 223-227.

Sassa, H., H. Kakui and M. Minamikawa. 2009. Pollen-expressed F-box gene family and mechanism of S-RNase-based gametophytic self-incompatibility (GSI) in Rosaceae. Sex. Plant 
Reprod. 23: 39-44.

Sassa, H., H. Kakui, M. Miyamoto, Y. Suzuki, T. Hanada, K. Ushijima, M. Kusaba, H. Hirano and T. Koba. 2007. S locus F-box brothers: Multiple and pollen-specific F-box genes with $S$ haplotype-specific polymorphisms in apple and Japanese pear. Genetics 175: 1869-1881.

Sassa, H., T. Nishio, Y. Kowyama, H. Hirano, T. Koba and H. Ikehashi. 1996. Self-incompatibility $(S)$ alleles of the Rosacae encode members of a distinct class of the T2/S ribonuclease superfamily. Mol. Gen. Genet. 250: 547-557.

Sijacic, P., X. Wang, A. L. Skirpan, Y. Wang, P. E. Dowd, A. G. McCubbin, S. Huang and T. Kao. 2004. Identification of the pollen determinant of $S$-RNase-mediated selfincompatibility. Nature 429: 302-305.

Sims, T. L. and M. Ordanic. 2001. Identification of a Sribonuclease-binding protein in Petunia hybrida. Plant Mol. Biol. 47: 771-783.

Sonneveld, T., T. P. Robbins, R. Bošković and K. R. Tobutt. 2001. Cloning of six cherry self-incompatibility alleles and development of allele-specific PCR detection. Theor. Appl. Genet. 102: 1046-1055.

Sonneveld, T., K. R. Tobutt and T. P. Robbins. 2003. Allelespecific PCR detection of sweet cherry self-incompatibility (S) alleles $S 1$ to $S 16$ using consensus and allele-specific primers. Theor. Appl. Genet. 107: 1059-1070.

Sonneveld, T., K. R. Tobutt, S. P. Vaughan and T. P. Robbins. 2005. Loss of pollen- $S$ function in two self-compatible selections of Prunus avium is associated with deletion/mutation of a $S$-haplotype specific F-box gene. Plant Cell 17: 37-51.

Soulard, J., N. Boivin, D. Morse and M. Cappadocia. 2014. eEF1A is an S-RNase binding factor in self-incompatible Solanum chacoense. PLoS ONE 9: e90206.

Soulard, J., X. Qin, N. Boivin, D. Morse and M. Cappadocia. 2013. A new dual-specific incompatibility allele revealed by absence of glycosylation in the conserved $\mathrm{C} 2$ site of a Solanum chacoense S-RNase. J. Exp. Bot. 64: 1995-2003.

Steinbachs, J. E. and K. E. Holsinger. 2002. S-RNase-mediated gametophytic self-incompatibility is ancestral in eudicots. Mol. Biol. Evol. 19: 825-829.

Sun, P. and T. Kao. 2013. Self-incompatibility in Petunia inflata: The relationship between a self-incompatibility locus F-box protein and its non-self S-RNases. Plant Cell 25: 470-485.

Sutherland, B. G., T. P. Robbins and K. R. Tobutt. 2004. Primers amplifying a range of Prunus $S$-alleles. Plant Breed. 123: 582-584.

Tamura, K., G. Stecher, D. Peterson, A. Filipski and S. Kumar. 2013. MEGA6: molecular evolutionary genetics analysis version6.0. Mol. Biol. Evol. 30: 2725-2729.

Tao, R. and A. F. Iezzoni. 2010. The S-RNase-based gametophytic self-incompatibility system in Prunus exhibits distinct genetic and molecular feature. Sci. Hortic. 123: 423-433.

Tao, R. and D. Matsumoto. 2012. S locus mutation and selfcompatibility in stone fruits. Acta Hortic. 967: 105-111.

Tao, R., A. Watari, T. Hanada, T. Habu, H. Yaegaki, M. Yamaguchi and H. Yamane. 2007. Self-compatible peach (Prunus persica) has mutant versions of the $S$ haplotypes found in self-incompatible Prunus species. Plant Mol. Biol. 63: 109-123.

Tao, R., H. Yamane, H. Sassa, H. Mori, T. M. Gradziel, A. M. Dandekar and A. Sugiura. 1997. Identification of stylar RNases associated with gametophytic self-incompatibility in almond (Prunus dulcis). Plant Cell Physiol. 38: 304-311.

Tao, R., H. Yamane, A. Sugiura, H. Murayama, H. Sassa and H. Mori. 1999. Molecular typing of $S$-alleles through identification, characterization and cDNA cloning for S-RNases in sweet cherry. J. Amer. Soc. Hort. Sci. 124: 224-233.
Tsukamoto, T., N. R. Hauck, R. Tao, N. Jiang and A. F. Iezzoni. 2006. Molecular characterization of three non-functional $S$ haploytpes in sour cherry (Prunus cerasus). Plant Mol. Biol. 62: 371-383.

Tsukamoto, T., N. R. Hauck, R. Tao, N. Jiang and A. F. Iezzoni. 2010. Molecular and genetic analyses of four nonfunctional $S$ haplotype variants derived from a common ancestral $S$ haplotype identified in sour cherry (Prunus cerasus L.). Genetics 184: 411-427.

Tsukamoto, T., D. Potter, R. Tao, C. P. Vieira, J. Vieira and A. F. Iezzoni. 2008a. Genetic and molecular characterization of three novel $S$-haplotypes in sour cherry (Prunus cerasus L.). J. Exp. Bot. 59: 3169-3185.

Tsukamoto, T., R. Tao and A. F. Iezzoni. 2008b. PCR markers for mutated $S$-haplotypes enable discrimination between selfincompatible and self-compatible sour cherry selections. Mol. Breed. 21: 67-80.

Ushijima, K., H. Sassa, A. M. Dandekar, T. M. Gradziel, R. Tao and H. Hirano. 2003. Structural and transcriptional analysis of the self-incompatibility locus of almond: identification of a pollen-expressed F-box gene with haplotype-specific polymorphism. Plant Cell 15: 771-781.

Ushijima, K., H. Sassa, M. Tamura, M. Kusaba, R. Tao, T. M. Gradziel, A. M. Dandekar and H. Hirano. 2001. Characterization of the $S$-locus region of almond (Prunus dulcis): Analysis of a somaclonal mutant and a cosmid contig for an $S$ haplotype. Genetics 158: 379-386.

Ushijima, K., H. Sassa, R. Tao, H. Yamane, A. M. Dandekar, T. M. Gradziel and H. Hirano. 1998. Cloning and characterization of cDNAs encoding S-RNases from almond (Prunus dulcis): primery structural features and sequence diversity of the S-RNases in Rosaceae. Mol. Gen. Genet. 260: 261-268.

Ushijima, K., H. Yamane, A. Watari, E. Kakehi, N. R. Hauck, A. F. Iezzoni and R. Tao. 2004. The $S$ haplotype-specific Fbox protein gene, $S F B$, is defective in self-compatible haplotypes of Prunus avium and P. mume. Plant J. 39: 573-586.

Uwate, W. J. and J. Lin. 1980. Cytological zonation of Prunus avium L. pollen tubes in vivo. J. Ultrastruct. Res. 71: 173184.

Vieira, J., P. G. Ferreira, B. Aguiar, N. A. Fonseca and C. P. Vieira. 2010. Evolutionary patterns at the RNase based gametophytic self-incompatibility system in two divergent Rosaceaae groups (Maloideae and Prunus). BMC Evol. Biol. 10: 200.

Vieira, J., N. A. Fonseca and C. P. Vieira. 2008a. An S-RNasebased gametophytic self-incompatibility system evolved only once in eudicots. J. Mol. Evol. 67: 179-190.

Vieira, J., N. A. Fonseca and C. P. Vieira. 2009. RNase-based gametophytic self-incompatibility evolution: Questioning the hypothesis of multiple independent recruitments of the $S$ pollen gene. J. Mol. Evol. 69: 32-41.

Vieira, J., R. Morales-Hojas, R. A. M. Santos and C. P. Vieira. 2007. Different positively selected sites at the gametophytic self-incompatibility pistil $S$-RNase gene in the Solanaceae and Rosaceae (Prunus, Pyrus, and Malus). J. Mol. Evol. 65: $175-185$.

Vieira, J., E. Teles, R. A. M. Santos and C. P. Vieira. 2008b. Recombination at Prunus $S$-locus region SLFL1 gene. Genetics 180: 483-491.

Vilanova, S., M. L. Badenes, L. Burgos, J. Martinez-Calvo, G. Llácer and C. Romero. 2006. Self-compatibility of two apricot selections is associated with two pollen-part mutations of different nature. Plant Physiol. 142: 629-641.

Wang, N. and T. Kao. 2012. Self-incompatibility in Petunia: a self/nonself-recognition mechanism employing $S$-locus $\mathrm{F}$ box proteins and S-RNase to prevent inbreeding. WIREs 
Dev. Biol. 1: 267-275.

Wang, H. and Y. Xue. 2005. Subcellular localization of the $S$ locus F-box protein AhSLF-S $\mathrm{S}_{2}$ in pollen and pollen tubes of self-incompatible Antirrhinum. J. Integr. Plant Biol. 47: 7683.

Wang, S., H. Kakui, S. Kikuchi, T. Koba and H. Sassa. 2012. Interhaplotypic heterogeneity and heterochromatic features may contribute to recombination suppression at the $S$ locus in apple (Malus $\times$ domestica). J. Exp. Bot. 63: 4983-4990.

Wang, Y., T. Tsukamoto, K. W. Yi, X. Wang, S. Huang, A. G. McCubbin and T. Kao. 2004. Chromosome walking in the Petunia inflata self-incompatibility ( $S$-) locus and gene identification in an $881-\mathrm{kb}$ contig containing $S_{2}$-RNase. Plant Mol. Biol. 54: 727-742.

Wang, Y., X. Wang, A. G. McCubbin and T. Kao. 2003. Genetic mapping and molecular characterization of the selfincompatibility $(S)$ locus in Petunia inflata. Plant Mol. Biol. 53: 565-580.

Wang, C., J. Wu, G. Xu, Y. Gao, G. Chen, J. Wu and S. Zhang. 2010. S-RNase disrupts tip-localized reactive oxygen species and induces nuclear DNA degradation in incompatible pollen tube of Pyrus pyrifolia. J. Cell Sci. 123: 4301-4309.

Wang, C., G. Xu, X. Jiang, G. Chen, J. Wu, H. Wu and S. Zhang. 2009. S-RNase triggers mitochondrial alteration and DNA degradation in the incompatible pollen tube of Pyrus pyrifolia in vitro. Plant J. 57: 220-229.

Watari, A., T. Hanada, H. Yamane, T. Esumi, R. Tao, H. Yaegaki, M. Yamaguchi, K. Beppu and I. Kataoka. 2007. A low transcriptional level of $S^{e}$-RNase in the $S^{e}$-haplotype confers self-compatibility in Japanese plum. J. Amer. Soc. Hort. Sci. 132: 396-406.

Wheeler, D. and E. Newbigin. 2007. Expression of 10 S-class SLF-like genes in Nicotiana alata pollen and its implications for understanding the pollen factor of S locus. Genetics 177: 2171-2180.

Williams, J. S., J. P. Der, C. W. dePamphilis and T. Kao. 2014a. Transcriptome analysis reveals the same 17 S-locus F-box genes in two haplotypes of the self-incompatibility locus of Petunia inflata. Plant Cell 26: 2873-2888.

Williams, J. S., C. A. Natale, N. Wang, S. Li, T. R. Brubaker, P. Sun and T. Kao. 2014b. Four previously identified Petunia inflata S-locus F-box genes are involved in pollen specificity in self-incompatibility. Mol. Plant 7: 567-569.

Wünsch, A. and J. I. Hormaza. 2004. Genetic and molecular analysis in 'Christobalina' sweet cherry, a spontaneous selfcompatible mutant. Sex. Plant Reprod. 17: 203-210.

Wünsch, A., R. Tao and J. I. Hormaza. 2010. Self-compatibility in 'Christobalina' sweet cherry is not associated with duplications or modified transcription levels of $S$-locus genes. Plant Cell Rep. 29: 715-721.

Xu, C., M. Li, J. Wu, H. Guo, Q. Li, Y. Zhang, J. Chai, T. Li and Y. Xue. 2013. Identification of a canonical SCF ${ }^{\text {SLF }}$ complex involved in S-RNase-based self-incompatibility of Pyrus (Rosaceae). Plant Mol. Biol. 81: 245-257.

Xue, Y., R. Carpenter, H. G. Dickinson and E. S. Coen. 1996. Origin of allelic diversity in Antirrhinum $S$ locus RNases. Plant Cell 8: 805-814.

Xue, Y., Y. Zhang, Q. Yang, Q. Li, Z. Cheng and H. G. Dickinson. 2009. Genetic features of a pollen-part mutation suggest an inhibitory role for the Antirrhinum pollen selfincompatibility determinant. Plant Mol. Biol. 70: 499-509.

Yamane, H. and R. Tao. 2009. Molecular basis of self(in)compatibility and current status of $S$-genotyping in rosaceous fruit trees. J. Japan. Soc. Hort. Sci. 78: 137-157.

Yamane, H., K. Fukuta, D. Matsumoto, T. Hanada, G. Mei, T.
Habu, Y. Fuyuhiro, S. Ogawa, H. Yaegaki, M. Yamaguchi and R. Tao. 2009. Characterization of a novel selfcompatible $S^{3^{\prime}}$ haplotype leads to the development of a universal PCR marker for two distinctly originated selfcompatible $S$ haplotypes in Japanese apricot (Prunus mume Sieb. et Zucc.). J. Japan. Soc. Hort. Sci. 78: 40-48.

Yamane, H., K. Ikeda, N. R. Hauck, A. F. Iezzoni and R. Tao. 2003a. Self-incompatibility $(S)$ locus region of the mutated $S^{6}$-haplotype of sour cherry (Prunus cerasus) contains a functional pollen $S$ allele and a non-functional pistil $S$ allele. J. Exp. Bot. 54: 2431-2437.

Yamane, H., K. Ikeda, K. Ushijima, H. Sassa and R. Tao. 2003b. A pollen-expressed gene for a novel protein with an F-box motif that is very tightly linked to a gene for S-RNase in two species of cherry, Prunus cerasus and P. avium. Plant Cell Physiol. 44: 764-769.

Yamane, H., K. Ushijima, H. Sassa and R. Tao. 2003c. The use of the $S$ haplotype-specific F-box protein gene, $S F B$, as a molecular marker for $S$-haplotypes and self-compatibility in Japanese apricot (Prunus mume). Theor. Appl. Genet. 107: $1357-1361$.

Yang, Q., D. Zhang, Q. Li, Z. Cheng and Y. Xue. 2007. Heterochromatic and genetic features are consistent with recombination suppression of the self-incompatibility locus in Antirrhinum. Plant J. 51: 140-151.

Yu, P., X. Chen, Q. Meng, Y. Zheng, X. Shen and X. Chen. 2010. Three nonfunctional $S$-haplotypes in self-compatible tetraploid Chinese cherry (Prunus pseudocerasus L. cv. Taixiaohongying). Euphytica 174: 143-151.

Yuan, H., D. Meng, A. Gu, W. Li, A. Wang, Q. Yang, Y. Zhu and T. Li. 2014. A novel gene, MdSSK1, as a component of the SCF complex rather than $M d S B P 1$ can mediate the ubiquitination of $S$-RNase in apple. J. Exp. Bot. 65: 3121-3131.

Zhang, X., X. Chen, Q. Meng, Y. Jiang, Y. Zheng and X. Chen. 2010. Transcript and sequence analysis of S-RNases in selfcompatible tetraploid Chinese cherry (Prunus pseudocerasus L.). Agric. Sci. China 9: 792-798.

Zhao, L., J. Huang, Z. Zhao, Q. Li, T. Sims and Y. Xue. 2010. The Skp1-like protein SSK1 is required for cross-pollen compatibility in S-RNase-based self-incompatibility. Plant J. 62: 52-63.

Zheng, N., B. A. Schulman, L. Song, J. J. Miller, P. D. Jeffrey, P. Wang, C. Chu, D. M. Koepp, S. J. Elledge, M. Pagano, J. W. Conaway, J. W. Harper and N. P. Pavletich. 2002. Structure of the Cul1-Rbx1-Skp1-F-box ${ }^{\text {Skp2 }}$ SCF ubiquitin ligase complex. Science 416: 703-709.

Zhou, J., F. Wang, W. Ma, Y. Zhang, B. Han and Y. Xue. 2003. Structural and transcriptional analysis of $S$-locus F-box genes in Antirrhinum. Sex. Plant Reprod. 16: 165-177.

Zisovich, A. H., R. A. Stern, G. Sapir, S. Shafir and M. Goldway. 2004. The RHV region of S-RNase in European pear (Pyrus communis) is not required for the determination of specific pollen rejection. Sex. Plant Reprod. 17: 151-156.

Zurek, D. M., B. Mou, B. Beecher and B. A. McClure. 1997. Exchanging sequence domains between S-RNase from Nicotiana alata disrupts pollen recognition. Plant J. 11: 797808.

Zuriaga, E., J. V. Muñoz-Sanz, L. Molina, M. L. Badenes and C. Romero. 2012. Physical mapping of a pollen modifier locus controlling self-incomaptibility in apricot and synteny analysis within the Rosaceae. Plant Mol. Biol. 79: 229-242.

Zuriaga, E., J. V. Muñoz-Sanz, L. Molina, A. D. Gisbert, M. L. Badenes and C. Romero. 2013. An S-locus independent polen factor confers self-compatibility in 'Katy' apricot. PLoS ONE 8: e53947. 